\title{
Las marcas de uso: despectivo en el DRAE
}

\author{
Cecilio Garriga \\ Universidad Rovira i Virgill (Tarragona)
}

\section{INTRODUCCIÓN}

Los diccionarios han recogido tradicionalmente una serie de indicaciones sobre el uso, con el propósito de orientar al lector en la utilización correcta de una determinada pieza léxica. Mediante esas indicaciones se limita la posibilidad de aparición de un elemento en un determinado contexto o situación comunicativa. El avance de la técnica lexicográfica y la proliferación de trabajos teóricos encaminados a hacer más rigurosa esta tarea producen un aumento del interés por este tipo de información, que hasta ahora no se había considerado fundamental para el usuario'.

En efecto, no hay ningún lexicógrafo que niegue la necesidad de reflejar en el diccionario la información sobre el uso. Desde los ya clásicos estudios de L. Zgusta (1971) o de J. Rey-Debove (1971), a los modernos trabajos de S. Landau (1984) o de B. Svensén (1987), y especialmente en los recogidos en la Enciclopedia Internacional de Lexicografía (F. Hausmann et al., 1989-1991), además de otros estudios parciales publicados en revistas especializadas ${ }^{2}$, se observa un aumento de la atención prestada a este tema. Este interés está motivado por la intención de proporcionar al usuario una mayor información contextual, que haga posible la producción de mensajes, no solo la descodificación ${ }^{3}$. Porque, como dice l. Bosque ${ }^{4}$, la escasa información contextual es uno de los mayores defectos de los diccionarios actuales. Pierre Corbin ${ }^{5}$ señala que una de

1 Los diccionarios modernos, como apunta P. CoRBIN (1989, p. 674) llegan incluso a utilizar la presencia de esta información como argumento publicitario. Así, en la cubierta posterior del Petit Robert (A. REY, J. REY-DEBOVE, 1990) se dice que contiene "les niveaux de langue, du très familier et de l'argotique au plus littéraire".

2 Conviene citar, por su tratamiento de este aspecto en los diccionarios, los estudios de P. IMBS (1969), Ch. Girardin (1987) y P. A. Messelaar (1988). En F. J. Hausmann (1989) se puede hallar una completa bibliografía sobre los diferentes tipos de marcas en lexicografía.

3 H. HERnÁndEZ (1990, p. 161) se queja de que los diccionarios actuales “(...) son obras meramente interpretativas, descodificadoras, que muy bien pueden servir al usuario para averiguar el sentido ignorado de una determinada palabra, pero muy pocas veces valen para la codificación".

4 Vid. I. BOSQUE (1982), p. 118.

5 Vid. P. CORBIN (1991), p. 166. 
las orientaciones futuras de la lexicografía francesa monolingüe pasa por la abundancia de este tipo de indicaciones, y añade que deben ser "explicitées et aussi désidéologisées que possible"6.

La observación de P. Corbin no es gratuita, ya que todos los autores reconocen la dificultad de establecer un criterio coherente, riguroso y sistemático para esta información en las obras lexicográficas. Y es que, como apunta A. Rey ${ }^{7}$, las indicaciones que se utilizan en los diccionarios raramente están explicadas, con frecuencia son implícitas y dependen del juicio del lexicógrafo, que se ve influido por factores subjetivos como su propia competencia lingüística, su formación u otros criterios extralingüísticos que utiliza para establecerlas ${ }^{8}$. Todo ello genera una práctica lexicográfica intuitiva, poco rigurosa, cercana a la que el hablante nativo tiene debido a su propia competencia. Pierre Corbin ${ }^{9}$ expresa, mediante estas palabras, las dificultades a las que se enfrenta la lexicografía en este aspecto:

"La mention de termes génériques d'extension incertaine (le plus souvent niveaux de langue, quelque fois aussi marques stylistiques, registres de langue, marques d'usage), celle de quelques marques (pas necessairement stylistiques / diastratiques) non caracterisées et une distinction insuffisamment tranchée entre ce qui relève de la sélection de la nomenclature et ce qui touche au marquage proprement dit des entrées selectionées constituent, dans les panachages aux proportions variables, les ingrédients de la "théorie" du marquage propre aux dictionnaires".

Algunos autores hacen propuestas interesantes, como F. J. Hausmann ${ }^{10}$, quien presenta un modelo de marcas que, aunque es más riguroso que los métodos utilizados actualmente, no asegura una base empírica y teórica segura.

Hay otro aspecto también importante, fundamental para que esta información sea clara y sistemática. Como explica J. Rey-Debove ${ }^{11}$, toda la información que contenga un diccionario debe expresarse con un metalenguaje claro, que normalice el discurso lexicográfico y ahorre esfuerzos al usuario. Por tanto, hay que evitar que la información sobre el uso aparezca implícitamente, en el interior de las definiciones ${ }^{12}$. Se hace necesaria una codificación que permita hacerla explícita, reservándole un espacio fijo en el artículo lexicográfico, que facilite su identificación. La tendencia general es distribuir en el léxico las llamadas marcas de uso, en forma de abreviaturas. Estas abreviaturas se recogen en las tablas iniciales de los diccionarios, aunque proporcionando una in-

6 Y añade: "comme Le Grand Robert de la langue française".

7 Vid. A. ReY (1990), pp. 17-18.

8 Vid. S. ETTinger (1982), p. 376.

9 Vid. P. CORBIN (1989), p. 674.

10 Vid. F. Hausmann (1989), pp. 650 y ss.

11 Vid. J. ReY-Debove (1989), p. 309.

12 En este sentido, valen las palabras de B. V. Gemmincen (1990, p. 33) a propósito del diccionario de Oudin: "On peut [...] se demander si, exception faite des marques d'usage explicites, les informations sémantiques (équivalents et définitions) ne sont pas en mesure de caractériser indirectement un lemme donné". 
formación poco exhaustiva sobre su valor. El otro elemento que ayuda a asegurar la coherencia del discurso metalexicográfico es, según P. Corbin ${ }^{13}$, el prólogo. Así, en el prólogo y en la tabla de abreviaturas es donde se exponen los principios y convenciones adoptados por los lexicógrafos. 0 donde se deberían exponer, porque lo cierto es que raramente encontramos en los prólogos comentarios que ayuden a interpretar las marcas de uso, y aún menos en las tablas de abreviaturas, donde se limitan a dar la forma sin abreviar que representa cada una de ellas ${ }^{14}$.

Esta situación hace que se deba cuestionar la equivalencia que frecuentemente se establece entre marca y abreviatura. Ciertamente, la abreviatura puede ser una técnica para proporcionar esta información en los diccionarios, pero no la única ${ }^{15}$. Y para que lo sea, se requiere una conciencia clara por parte del lexicógrafo, que debe utilizar las abreviaturas con una intención codificadora, y no sólo como un recurso tipográfico al que se puede acudir para ganar espacio. Además, sería necesario clarificar el concepto de marcado vs. no marcado en el nivel léxico, lo que permitiría a la lexicografía aplicar esta distinción con más rigor.

Una vez hechas estas consideraciones previas, voy a examinar algunas de las cuestiones mencionadas en el Diccionario de la RAE. En primer lugar me referiré al estado de las marcas de uso en la última edición (DRAE-1992) y proporcionaré datos concretos sobre la presencia de cada una de ellas en el inventario académico, así como de las diferencias respecto a la edición anterior (DRAE-1984). En segundo lugar, me voy a centrar en el estudio detallado de una de estas marcas, la de despectivo, una de las más importantes tanto por el número de acepciones en que aparece, como por su complejidad. Para ello atenderé a dos aspectos: el tipo de palabras que en el DRAE-1992 llevan esta indicación, y la forma como esta información se expresa. Dado el carácter del repertorio académico, elaborado a partir de incorporaciones y enmiendas sobre la base de AUTORIDADES, me parece importante conocer el desarrollo histórico de esta indicación, por lo que dedicaré un apartado a su evolución, en el que destacaré las ediciones más importantes para la configuración de la marca. Este panorama ayudará a comprender el porqué de su estado actual. En la conclusión podremos constatar que el $D R A E$ es un buen ejemplo de la preocupación de la lexicografía por suministrar información sobre el uso, y de las limitaciones que los métodos tradicionales tienen para hacerlo con una mínima coherencia. En el apéndice final proporciono el repertorio de todas las acepciones que en el DRAE-1992 llevan la indicación de despectivo, con la información añadida de la edición en la que se incorporan al Diccionario académico y de la edición en que toman la marca (Vid. Apéndice).

13 Vid. P. CORBIN (1989), p. 673.

14 Dos excepciones importantes, entre los grandes diccionarios, son el Petit Robert (A. REY, J. Rey-Debove, 1990) y el Longman Dictionary of Contemporary English (D. Summers, 1992).

15 Vid. F. J. Hausmann (1989), p. 649. 


\section{LAS MARCAS DE USO EN EL DRAE}

Si nos fijamos en los dos aspectos mencionados más arriba, el prólogo y la tabla de abreviaturas, encontramos, en las Advertencias para el uso de este diccionario (DRAE-1992, p. XXI), la única referencia a esta cuestión, al decir, dentro del epígrafe dedicado al orden de acepciones, que:

"Dentro de cada artículo van colocadas por este orden las diversas acepciones de los vocablos: primero las de uso corriente; después las anticuadas, las familiares, las figuradas, las provinciales e hispanoamericanas, y, por último, las técnicas y de germanía"16.

De ahí pasamos a las Abreviaturas empleadas en este diccionario (DRAE-1992, p. XXIX), y encontramos diversas abreviaturas que se pueden reunir bajo la consideración de marcas de uso:

$\begin{array}{ll}\text { coloq. } & \text { coloquial } \\ \text { despect. } & \text { despectivo o despectiva } \\ \text { fam. } & \text { familiar } \\ \text { fest. } & \text { festivo o fiesta } \\ \text { irón. } & \text { irónico o irónica } \\ \text { poét. } & \text { poético o poética } \\ \text { pop. } & \text { popular } \\ \text { rur. } & \text { rural } \\ \text { rúst. } & \text { rústico } \\ \text { vulg. } & \text { vulgar }\end{array}$

La falta de más indicaciones sobre el valor de estas abreviaturas hace difícil determinar cuál puede ser la diferencia entre familiar y coloquial, o entre rural y rústico; cuál es el alcance de la indicación de popular, si se refiere a un nivel o a un estilo de lengua; si poético es una indicación técnica o si se puede asimilar al nivel formal; qué significa festivo, etc.

Después de un trabajo de vaciado de todas aquellas acepciones que se recogen con alguna de estas indicaciones, realizado a partir de una lectura detenida del DRAE-1984 y del DRAE-1992, he podido observar que en el repertorio académico se utilizan diferentes sistemas a la hora de suministrar esta información. Me he visto obligado, por

16 Estas Advertencias aparecen por primera vez en la $12^{\mathrm{a}}$ ed. (DRAE-1884) con el título de Reglas para el uso de este diccionario, y se mantienen así hasta que cambian en la 19a ed. (DRAE-1970). Concretamente este epígrafe sufre algunas modificaciones: precisamente en el DRAE-1970 las acepciones de germanía pasan a último lugar, "honor" que hasta ese momento les cabía a las técnicas; por otro lado, las palabras de uso corriente eran de uso vulgar y corriente hasta la $21^{\text {a }}$ ed. (DRAE-1992), lo que constituía una contradicción, porque la abreviatura de vulgar se introduce en la $15^{\mathrm{a}}$ ed. (DRAE1925). 
tanto, a tener en cuenta no solo aquellas acepciones que presentan alguna de estas abreviaturas, sino también las que expresan esta información mediante comentarios implícitos en la definición. El recuento de las acepciones recogidas proporciona los siguientes datos ${ }^{17}$ :

\begin{tabular}{|lrrrrrr|}
\hline & \multicolumn{2}{c}{$\begin{array}{c}\mathrm{n}^{\circ} \text { total } \\
\text { de acepc. }\end{array}$} & \multicolumn{2}{c|}{$\begin{array}{c}\text { incorporaciones } \\
\text { en 1992, y \% }\end{array}$} & \multicolumn{2}{c|}{$\begin{array}{c}\text { acep. que toman } \\
\text { la marca en } 1992\end{array}$} \\
\hline coloquial & 31 & $0,26 \%$ & 23 & $74,19 \%$ & 6 & $19,35 \%$ \\
despectivo & 349 & $2,99 \%$ & 45 & $12,89 \%$ & 28 & $8,02 \%$ \\
familiar & 10.528 & $90,26 \%$ & 689 & $6,54 \%$ & 111 & $1,05 \%$ \\
festivo & 55 & $0,47 \%$ & 7 & $12,7 \%$ & 1 & $1,81 \%$ \\
irónico & 106 & $0,9 \%$ & 10 & $9,43 \%$ & 7 & $6,6 \%$ \\
poético & 258 & $2,21 \%$ & 6 & $2,32 \%$ & 8 & $3,1 \%$ \\
popular & 14 & $0,12 \%$ & 4 & $28,57 \%$ & 6 & $42,85 \%$ \\
rural & 45 & $0,38 \%$ & 17 & $37,77 \%$ & 28 & $62,22 \%$ \\
rústico & 7 & $0,06 \%$ & 1 & $14,28 \%$ & 2 & $28,57 \%$ \\
vulgar & 269 & $2,3 \%$ & 74 & $27,5 \%$ & 34 & $12,63 \%$ \\
& 11.662 & & 876 & $7,51 \%$ & 231 & $1,98 \%$ \\
\hline
\end{tabular}

Estos datos dan a entender ya varias cosas. En primer lugar, la desigual distribución de estas marcas en el DRAE. De las 11.662 acepciones que, según mi recuento, presentan alguna de estas indicaciones en la $21^{\text {a }}$ ed. (DRAE-1992), existe una que tiene un peso propio: la de familiar, que es, además, la que más incorporaciones registra en la última edición. Hay que añadir que de estas 10.528 acepciones, 5.554 corresponden a frases o locuciones, más de la mitad. Junto a familiar, debe considerarse la indicación de coloquial, por su afinidad, pues se hace difícil trazar el límite del dominio de cada una de ellas, si es que no se superponen. En cualquier caso, obsérvese que es una marca que, a pesar de su escasa presencia, prácticamente aparece en esta edición: las 23 acepciones que se incorporan en el DRAE-1992, más las 6 acepciones que ya estaban en el DRAE-1984 pero que reciben la marca en el DRAE-1992, constituyen 29 de las 31 acepciones totales. Téngase en cuenta que esta abreviatura aparece por primera vez en la $20^{\mathrm{a}}$ edición (DRAE-1984).

Las indicaciones de popular, rústico y rural constituyen un grupo casi insignificante por su número, también de muy reciente aparición en el Diccionario: la abreviatura

17 En la primera columna aparece el número total de acepciones con cada una de las marcas, con el porcentaje que representa sobre las 11.662 registradas; en la segunda, cuántas acepciones se han incorporado en la última edición, y qué porcentaje suponen respecto a las que hay de cada una de las marcas; en la tercera, cuántas acepciones que ya estaban en el DRAE-1984 reciben estas indicaciones en el $D R A E-1992$, y su porcentaje respecto al número de acepciones marcadas de esa manera en la última edición. 
de popular en el DRAE-1956, la de rústico en el DRAE-1970, y la de rural, la más representativa de las tres, en esta última edición. También es la más uniforme en cuanto al tipo de palabras que recoge, pues se trata de una serie de americanismos relacionados todos ellos con el mundo de los gauchos, incorporados casi todos en esta últma edición, como bolear 11 'rur. Argent. Empinarse el potro sobre las patas y caer de lomo', o tirador 10 'rur. Argent. Cinturón de cuero curtido, propio de la vestimenta del gaucho [...]'. En cualquier caso es dudosa la coherencia de la marca con el tipo de palabras a que se refiere.

La marca de vulgar experimenta un crecimiento importante en las últimas ediciones, coincidiendo con una apertura del Diccionario al léxico malsonante, aunque también incluye un grupo importante de palabras que son arcaísmos léxicos que se conservan en la lengua poco culta, como arrempujar, muncho, o priesa ${ }^{18}$. En cambio, la marca de poético, que viene de las primeras ediciones académicas, llega a nuestros días perfectamente perfilada, y recoge una serie de cultismos, en muchos casos epítetos aplicables a elementos mitológicos como altitonante, nemoroso o pierio, y arcaísmos como agora 2, aqueste o asaz. Por tanto, se refiere únicamente a la poesía de nuestros clásicos.

Las indicaciones de festivo e irónico son poco relevantes por su número, y siguen un proceso de formación parecido, que arranca de AUTORIDADES. A lo largo de las diferentes ediciones del DRAE van alternando con jocoso, humorístico, etc. Se trata de grupos heterogéneos de difícil clasificación, donde se pueden encontrar palabras como panderetólogo 'fest. En la tuna, el estudiante diestro en tocar la pandereta', o atropeIlaplatos 'fest. Criada o fregona torpe'. La marca de irónico se da más en frases y locuciones, donde se intenta explicar el contexto pragmático, y así tenemos, por ejemplo, no llegará la sangre al río (s. v. sangre), o tutumpote 'Sto. Dom. mandamás, el que todo lo puede, dicho con sent. irónico y despectivo'. La marca de despectivo es la más importante por su número, sin tener en cuenta, claro está, la de familiar. Pero a despectivo, como he anunciado, voy a dedicarle una atención especial. Las marcas de coloquial, familiar, festivo, irónico, poético, popular, rural y rústico quedan pendientes de un análisis más detallado.

Cabe mencionar, no obstante, que en el DRAE-1992 existe una serie de indicaciones, que no he recogido en mi inventario, y que podrían ser consideradas de uso, como 'en el lenguaje de la droga' (s. v. changa2 3, esnifada, polvo 4, o raya1 10) ${ }^{19}$, sobre todo si acepciones como anfeta, canuto1 5, colgar 11, colocar 4, drogata o drogota tienen marca de familiar. Se encuentra también una acotación del tipo 'en el lenguaje / léxico estudiantil' (s. v. cátedro, coladera 2, coladero 4), 'entre estudiantes' (s. v. chuleta 4, pasaturo), mientras que palabras como escabechina 2, fósil 6 o hacer novillos (s. v. novillo) tienen marca de familiar. El comentario 'en lenguaje infantil' se ha-

18 Para la marca de vulgar en el DRAE, véase C. GARRIGA (1994), donde se puede hallar una descripción detallada de las acepciones que tienen esta marca en la edición de 1992, y de la evolución que ha seguido a lo largo de la historia del Diccionario académico.

19 Mientras que en esnifada se incluye el comentario 'en el lenguaje de la droga', ni en esnifada 2 ni en esnifar se hace ninguna alusión a este hecho. 
lla en acepciones como chis1, drea, pipR, pupa 4; 'voz infantil' en papa1 2, o en a upa (s. v. upa), etc. Las acepciones chacho1, tata 3 y tato1 son 'voz de cariño'. Se dice que se utiliza 'en el lenguaje corriente / común' en foja 12 , gusano 2 o huevo. De cachirulo 5 se dice que 'se usa en estilo bajo', de guapo 5 'en estilo picaresco', y de darle a uno la gana (s. v. gana) 'en lenguaje poco culto'. En sextaferia se dice que 'está en uso en algunas aldeas', en modorrar que se usa 'entre pastores', nengún 'entre campesinos', y jitar 2 'solo en las montañas'. Estos ejemplos nos muestran hasta qué punto es necesaria la sistematización de esta información. De momento sirva este esbozo para tener una visión de conjunto.

\section{LA MARCA DE DESPECTIVO EN EL DRAE}

Julio Casares ${ }^{20}$ se preocupaba por cómo se podían reflejar los aspectos afectivos en el Diccionario, ante la dificultad de fijar usos que suelen ser subjetivos. Algunos están aceptados en la comunidad, y se deben a prejuicios dominantes en cada sociedad, 0 a determinadas asociaciones de ideas ${ }^{21}$. Otras veces, estas palabras se forman a partir de procesos morfológicos, mediante sufijación apreciativa, y especialmente con sufijos aumentativos y diminutivos a los que estos valores están ligados. Aunque, como expresa M. Lang ${ }^{22}$, resulta muy difícil determinar lo que es o no un sufijo apreciativo, porque en algunas ocasiones su capacidad emotiva se debe al significado de la base 0 al contexto léxico en que aparece.

A continuación veremos qué tratamiento recibe este tipo de palabras en el DRAE1992, y cuál ha sido su evolución hasta nuestros días.

\section{Situación en el DRAE-1992}

Para el examen de las 349 acepciones que, según mi recuento, en la última edición del DRAE aparecen con marca de despectivo, me voy a fijar en dos aspectos: en qué tipo de palabras se halla la marca, y cómo se expresa esta información.

\section{a) Tipo de palabras con marca de despectivo}

La ausencia de información sobre esta marca en el Preámbulo o en las Advertencias del DRAE hace pensar que quizá en el interior del diccionario, en el artículo correspondiente a este lema, se pueda encontrar alguna orientación al respecto. Así, bajo el lema despectivo, va, se puede leer en la $2^{\mathrm{a}}$ y la $3^{\mathrm{a}}$ acepciones:

21 Vid. S. Ullmann (1962), p. 261.

22 Vid. M. LANG (1990), pp. 126-127. 
2. Gram. Aplícase a la palabra que incluye idea de menosprecio en la significación del positivo de que procede; v. gr.: libraco, villorrio, poetastro, calducho. Ú. t. c. s. m.

3. Gram. Dícese también del sufijo que se añade a dicho positivo.

La definición del Diccionario sólo hace referencia a los despectivos por derivación, y los ejemplos que proporciona son todos derivados. Responden al esquema:

$$
\text { base }+ \text { sufijo apreciativo }
$$

Precisamente en esta última edición del DRAE se han incluido por primera vez, de forma más o menos sistemática, los sufijos en el cuerpo del Diccionario. Algunos de ellos, en su definición, hacen referencia al sentido despectivo que pueden aportar a las bases a las que se adjuntan para formar nuevas palabras. Concretamente son 20 los sufijos con esta información (Vid. apéndice):

$\begin{array}{llll}-a c o 2 & \text {-acho } & \text {-ajo } & \text {-alla } \\ -a n c o & -a n g a & -a n g o & \text {-astro } \\ -a z o & -d a & -e j o & -e t e \\ -i c a & -i j a & -i j o & -i j o ́ n \\ -o ́ n 1 & -r r o & -s c o & -u e l o\end{array}$

Efectivamente, esta idea da la primera pista sobre las palabras que se marcan como despectivas, que, en gran medida, se pueden clasificar por sufijos. En total son 158 de las 349 totales, lo que significa que casi la mitad tienen una motivación morfológica ${ }^{23}$ :

-acho: amigacho 2, humoracho, libracho, poblacho, vulgacho.

-aco: bicharraco, bolchaco, carraca1 1, carraca 1 3, libraco, pajarraco.

-ada: americanada, americanada $2^{24}$, bufonada 2, chirinada, manjorrada.

-aje: compadraje, gringaje, hembraje 2.

-ajo: andrajo 3, atajo 6, cintajo, hatajo 2, hierbajo, latinajo, latinajo 2, moñajo, navajo, pispajo 3, tirajo, trapajo.

-alla: antigualla 4, clerigalla, gentualla.

-ango: fritanga, querindango, señoritingo.

-astro: camastro, criticastro, filosofastro, musicastro, politicastro, recalvastro. -ato: niñato 2.

-azo: bajonazo, carnaza 4, hornaza.

-ejo: bachillerejo, caballejo, caminejo, capeja, capitanejo 2, chillanejo, librejo

2, lugarejo, malejo, medianejo, palabreja, tipejo.

-engue: blandengue.

-ete: bajete, chafirete, mayorazguete, paporreta, soniquete, tatarrete.

23 En este listado solo he incluido aquellas palabras cuyo sentido despectivo lo aporta el sufijo. He omitido otras que, aunque también son derivados y despectivos, desarrollan este matiz por otras causas, como chochez, colaboracionista, compadraje, dominguero o ingeniosidad 2. Tampoco he tenido en cuenta verbos como discretear, gimotear, paporretear o ventajear, más discutibles (Vid. Apéndice).

24 Sin embargo, españolada 'acción, espectáculo u obra literaria que exagera el carácter español', aparece sin marca alguna. 
-ica: miedica.

-ija: repartija.

-il: abogadil, preceptoril.

-illo: asuntillo, corrillo, gentecilla 2, guindilla 3, guindilla 4, pasioncilla 2 , personilla, sabidillo, tinterillo.

-ín: borrachín, cachupín, casaquín, levitín.

-oche: pitoche

-ojo: matojo.

-ón: aldeón, alquilón, asnejón, camaranchón, comedión, copión1, coplón 2,

costurón 2, dramón, empollón, escopetón, escuderón, estudiantón, fondón2, grandulón, herrerón, ricachón, sargentona.

-ote: amigote, gimotear, machote 2, marquesote, palabrota, papelote1, perote, soldadote.

-orio: papelorio, vejestorio.

-orrio: aldeorrio, vidorria, villorrio.

-rro: aldeorro, ventorro.

-sco: abogadesco, camarillesco, chalanesco, liberalesco, sacristanesco.

-ucio: tontucio.

-uco: beatuco, carruco, casuca 2, feúco, frailuco, hermanuco, hijuco, miseriuca, monteruca, mujeruca.

-ucho: animalucho, barbucha, cafetucho, calducho, camucha, casucha, clarucho, cuartucho, delgaducho, feúcho, flacucho, papelucho, periodicucho.

-udo: anteojudo, crestudo.

-uelo: callejuela, escritorzuelo, estudiantuelo, jovenzuelo.

-ujo: papelujo.

-uncio: pajuncio.

-uno: frailuno.

-uza: carnuza, gentuza.

Como se puede observar, en este listado aparecen otros sufijos, además de los que el DRAE-1992 señala como susceptibles de aportar un sentido peyorativo. Se trata de los casos de: -aje, -ato, -il, -ín y -udo. Y hay otros que, simplemente, no aparecen en el Diccionario: -engue, -orio, -ucio, -uco, -ucho, -uncio, y -uno. Los casos de -asco, -esco, -isco, -izco, -usco, y -uzco los incluye la Academia en $-s c 0^{25}$.

Volviendo a la clasificación anterior, cabe destacar los 27 casos de formación regular que el mismo DRAE define como 'despect. de + base':

$\begin{array}{llll}\text { bachillerejo } & \text { barbucha } & \text { beatuco } & \text { bicharraco } \\ \text { caballejo } & \text { cafetucho } & \text { carruco } & \text { cintajo }\end{array}$

25 El Diccionario de Uso del Español (M. MouIner, 1966) recoge, s. v. despreciar, los sufijos "despectivos" -acho, -aco, -ajo, -alla, -anco, -ango, -ario, -astro, -sco, -ucio, -uco, -ugio, -ujar, -ujo, -uncho. Se dice que "el sufijo más netamente despectivo" es -ucho. Se hace referencia, además, al posible valor despectivo de otros sufijos como -eco, -ete, o -il. 


$\begin{array}{llll}\text { hierbajo } & \text { humoracho } & \text { liberalesco } & \text { matojo } \\ \text { medianejo } & \text { monteruca } & \text { moñajo } & \text { mujeruca } \\ \text { musicastro } & \text { navajo } & \text { periodicucho } & \text { pitoche } \\ \text { icachón } & \text { señoritingo } & \text { soniquete } & \text { tatarrete } \\ \text { tirajo } & \text { tontucio } & \text { trapajo } & \end{array}$

También se encuentran 8 acepciones definidas como: 'aum. despect.' (aumentativo despectivo): aldeón, asnejón, comedión, copión1, herrerón, hornaza, marquesote y soldadote; y otras 15 definidas como 'd. despect.' ('diminutivo despectivo'): bajete, caIlejuela, caminejo, casaquín, escritorzuelo, estudiantuelo, hijuco, homúnculo, jovenzuelo, levitín, lugarejo, malejo, mayorazguete, miseriuca y palabreja ${ }^{26}$.

Sin embargo, la presencia de estas acepciones en el Diccionario contradice las normas que la propia Academia anuncia en las Advertencias ${ }^{27}$, sobre todo cuando en esta edición se incluyen, como hemos visto, los sufijos. Por tanto, solo deberían aparecer en el Diccionario las formas lexicalizadas o, a lo sumo, aquellas que tuvieran además otras acepciones con significado no deducible.

Atendiendo al aspecto morfológico, hay que destacar otro conjunto significativo dentro de los despectivos, que está formado por palabras compuestas. Y así tenemos:

$\begin{array}{llll}\text { buchipluma } & \text { cagatinta } & \text { carricoche } & \text { chupacirios } \\ \text { chupalámparas } & \text { chupatintas } & \text { cojitranco } & \text { destripaterrones } \\ \text { rapavelas } & \text { saltatumbas } & \text { tiracuero } & \text { tragasantos }\end{array}$

El resto de las palabras que componen el grupo de despectivo es más heterogéneo, y buscar relaciones entre sus acepciones nos llevaría a un tratamiento caso por caso (Vid. Apéndice).

\section{b) Cómo se expresa la marca de despectivo}

Por lo que respecta a la forma como está expresado el valor de despectivo de una acepción, se observa que no hay un procedimiento único para hacerlo. Pero el método más frecuente es mediante la abreviatura despect. De las 349 acepciones que, según mi recuento, tienen esta indicación, 189 la expresan al principio, separada de la definición, caracterizándola como una información de otra naturaleza, y acercándose más a la codificación deseable. Veamos algunos ejemplos:

26 Y no menciono otros casos que, debido a la falta de homogeneidad de las definiciones, no se definen en estos términos, pero que tienen el mismo sentido. Sirvan como ejemplos asuntillo 'd. de asunto, negocio. Suele emplearse con diversos matices, irónico, despectivo, minorativo, etc.', escopetón 'aum. de escopeta. Ú. t. c. despect.', libraco 'despect. Libro despreciable', querindango 'despect. querido', etc. (Vid. Apéndice).

27 Dice el Diccionario (DRAE-1992, p. XXII): “Los diminutivos en -ico, -illo, -ito; los aumentativos en -ón, -azo, y los superlativos en -ísimo, cuya formación sea regular y conforme a las observaciones que se dan al fin del DicCIONARIO, no se incluyen en este, salvo el caso en que tengan acepción especial que merezca ser notada. (...) Tampoco se incluyen todos los adverbios en -mente, ni todos los diminutivos y despectivos en -ote, -uco, -uca, -ucho, -ucha, por ser de formación fácil y a menudo ocasional". 
casucha, cho. despect. Casa pequeña y mal construida.

clarucho, cha. despect. Aplícase a la sustancia desleída en cantidad excesiva de agua u otro líquido.

individuo, dua. 7. f. despect. Mujer despreciable.

saltatumbas. fig. y despect. fam. Clérigo que se mantiene principalmente de lo que gana asistiendo a los entierros.

Esta formulación también se da entre locuciones, como en:

carnaval. II ser una cosa un carnaval. 2. fig. y despect. Dícese del conjunto de informalidades y fingimientos que se reprochan en una reunión o en el trato de un negocio.

hambre. II ser un muerto de hambre. despect. Carecer de lo necesario, a pesar de lo que se aparenta.

Pero la indicación de despectivo se presenta otras veces mediante el adverbio despectivamente, ya en el interior de la definición. Así tenemos, por ejemplo:

empollón, na. Dícese, despectivamente, del estudiante que prepara mucho sus lecciones, y se distingue más por la aplicación que por el talento.

ingeniosidad. 2. fig. Expresión o idea artificiosa y sutil. Ú. por lo general despectivamente.

pijotero, ra. Se dice despectivamente de lo que produce hastío, cansancio u otras cosas, según el sustantivo a que se aplica.

A partir de aquí, se encuentra una serie de comentarios poco uniformes, a veces con diferencias solo formales, que matizan la información de despectivo. Todos se refieren a la frecuencia, pero unos aluden al sentido ${ }^{28}$ :

- Ú. con sent. despect.: babazorro, capitoste.

- En sentido despectivo: colaboracionista, fregona.

- En sent. despect.: churriguerismo2, cromo2 2, niño 5, pispajo 3.

- Ú. por lo común en sent. despect.: abogadesco, capilla 10.

- Suele usarse con sentido despectivo: artilugio.

- A veces se usa en sentido despectivo: fritanga.

- Ú. a veces en sent. despect.: desbarbado 2, policíaco.

- Ú. m. en / con sent. despect.: calaña1 2, capitanejo 2, chopa3, dramón, gringaje.

- Ú. t. en sent. despect.: caricatura 2, chirinada.

Otros hacen referencia al valor:

- Ú. frecuentemente con valor despectivo: borrachín.

- Suele emplearse con valor despectivo: niñato.

- Suele tener valor despectivo: carcamal1, compadreo.

28 Reproduzco literalmente la forma como el $D R A E$ expresa esta información para que se pueda apreciar la falta de homogeneidad. 
- A veces con valor despect.: runa2.

- En ocasiones, ú. con valor despect.: pigmeo.

0 al matiz, como en asuntillo; o al uso, como en pesetero; o a la significación, como en sofista. Aún están los que solo se refieren a la frecuencia:

- A veces despectivo: tener enchufe (s. v. enchufe).

- Ú. m. c. despect.: grandulón, no tener uñas para guitarrero (s. v. uña).

- Ú. t. c. despect.: escopetón.

- Ú. c. despect.: discretear.

La idea de menosprecio que expresa la indicación de despectivo se encuentra señalada también por el comentario de peyorativo, que en el DRAE se define de la siguiente forma:

peyorativo, va. adj. Dícese de aquellas palabras o modos de expresión que indican una idea desfavorable.

No hay ninguna abreviatura que se refiera a peyorativo en el Diccionario, por lo que esta indicación aparece siempre en forma de comentario en el interior de las definiciones, tan poco sistematizada como la de despectivo:

- En sent. peyorativo: ventajear.

- Ú. por lo común en sent. peyorativo: lobos de una camada (s. v. lobo).

- Ú. con frecuencia en sent. peyorativo: academizar.

- Ú. frecuentemente con sentido peyorativo: especular2 4.

- Ú. frecuentemente con carácter peyorativo: paternalismo.

- Ú. frecuentemente con valor peyorativo: semiculto 2.

- Tómase, por lo regular, en sentido peyorativo: estar de manga (s. v. manga).

- Tómase ordinariamente en sentido peyorativo: peine.

- Tómase por lo común en sentido peyorativo: ratón de biblioteca (s. v. ratón).

- Se usa por lo general con sentido peyorativo: ser de lo que no hay (s. v. ser2).

- Se usa / Ú. generalmente en sentido peyorativo: acromado, amasar 5, bufonada 2, la cara se lo dice (s. v. cara), corrillo, Dios los cría y ellos se juntan (s. v. dios), fautor, fraguar, otra u otro que tal (s. v. otro), púa, sugestión, tal para cual (s. v. tal).

- Ú. m. en / con sentido / sent. peyorativo: bordear, ser alguien un caso (s. v. caso1), melifluamente, melifluo, repartija.

- Ú. t. en sent. peyorativo: caterva.

Hay que mencionar, además, otros comentarios menos frecuentes, también referidos al sentido de menosprecio que tiene una acepción. Aparece en alguna ocasión la fórmula en mal sentido (artería, artero), muy frecuente en ediciones pasadas, y que aún se mantenía en bastantes acepciones en el DRAE-1984, junto a la de en mala parte ${ }^{29}$.

29 Sirvan como ejemplos adlátere, amasar 5, anchura 6, bufonada 2, la cara se lo dice (s. v. cara), compadraje, corrillo, Dios los cría y ellos se juntan (s. v. dios), empatársela a uno (s. v. empatar), 
De puto se dice que es calificación denigratoria. La expresión desprecio se encuentra presente en la definición de diversas acepciones, como en ${ }^{30}$ : ¿qué alforja? (s. v. alforja), jarre allá! (s. v. arre), a buscar la cagada del lagarto (s. v. cagada), ser buena una cosa solo para echada a la calle (s. v. calle), ivaya usted al cielo! (s. v. cielo), dar al diablo una persona o cosa (s. v. diablo), digan, que de Dios dijeron (s. v. dios), mandar, o enviar, a una persona a la eme (s. v. eme), fu 2, váyase a espulgar un galgo (s. v. galgo), por un garbanzo no se descompone la olla (s. v. garbanzo), hijo de puta (s. v. hijo), eso está mandado recoger (s. v. mandar), de marras (s. v. marras), que te den, o que le den morcilla (s. v. morcilla), o en iqué niño envuelto, o muerto! (s. v. niño); veamos algunos ejemplos:

eme. Il mandar, o enviar, a una persona o cosa a la eme. fr. fig. y fam. de desprecio, en que eme es un eufemismo de mierda.

fu. 2. interj. de desprecio.

hijo. II hijo de puta. expr. injuriosa y de desprecio.

marras. II de marras. loc. que, complementando a un sustantivo, significa con humor o desprecio que lo significado por este es conocido sobradamente. Ha contado mil veces la aventura DE MARRAS. Vino a verte el individuo DE MARRAS.

Algunas palabras utilizadas en la definición transmiten un sentido negativo. Así ocurre con el término apodo, o con el verbo zaherir, (s. v. chucumeco), o con el verbo motejar (s. v. feúcho). Estos procedimientos eran muy utilizados en las primeras ediciones del DRAE, y en algunos casos han venido subsistiendo hasta hoy ${ }^{31}$.

También me parece interesante señalar la combinación de la indicación de despectivo con otras de las que aquí nos ocupan, en una misma acepción. Se pueden señalar, como ejemplos, los casos de:

- Coloquial y despectivo: joto.

- Vulgar y despectivo: baranda2, dar o hacer un corte de mangas (s. v. corte)

- Rural y despectivo: hembraje 2, sotreta.

- Irónico y despectivo: tutumpote.

Pero el grupo más importante es el formado por las palabras marcadas como despectivo y familiar, que alcanza el número de 58 . De ellas, 40 son acepciones:

fautor, gramática parda (s. v. gramática), latín 2, otro u otra que tal (s. v. otro), peine 8, púa 9, ser de lo que no hay (s. v. ser2), sugestión 2, tal para cual (s. v. tal). El número de orden de la acepción se refiere siempre al que tiene en el DRAE-1992.

30 Estas locuciones no están incluidas en el inventario que aparece en el apéndice, ni consideradas en los recuentos.

31 Por ejemplo, en el DRAE-1832 aparecen con el término apodo en la definición, palabras como: arrancapinos, bullebulle, carcamal, catacaldos, culón, lameplatos, licenciadillo, matasanos, papanatas, pelagatos, pendejo, pendón, pintamonas, etc. No cabe duda de su sentido negativo. Todas estas palabras tienen marca de familiar en el DRAE-1992. 


$\begin{array}{llll}\text { amasar } 5 & \text { bolchaco } & \text { cachupín } & \text { cagatinta } \\ \text { camucha } & \text { carcamal } & \text { cavernícola 2 } & \text { destripaterrones } \\ \text { enchufar } 5 & \text { enchufe } 4 & \text { enchufista } & \text { feúcho } \\ \text { feúco } & \text { finústico } & \text { flacucho } & \text { fondón 2 } \\ \text { frailuno } & \text { gabacho } 4 & \text { gabacho } 5 & \text { gramatiquear } \\ \text { gramatiquería } & \text { grandulón } & \text { guindilla 3 } & \text { guindilla 4 } \\ \text { latinajo } & \text { latinajo } 2 & \text { levitín } & \text { maracucho } \\ \text { marmota 4 } & \text { medianejo } & \text { miedica } & \text { peine } 8 \\ \text { púa 9 } & \text { roto } & \text { saltatumbas } & \text { sargentona } \\ \text { suficiencia } & \text { tinterillo } & \text { tragasantos } & \text { vidorria 2 }\end{array}$

Las otras 18 son expresiones: arrópese con ello (s. v. arropar1), la cara se lo dice (s. v. cara), ser alguien un caso (s. v. caso1), escardar cebollinos (s. v. cebollinos), dios los cría y ellos se juntan (s. v. dios), empatársela a uno (s. v. empatar), tener enchufe (s. v. enchufe), gramática parda (s. v. gramática), lobos de una camada (s. v. lobo), estar de manga (s. v. manga), lo de marras (s. v. marras), ojo de breque (s. v. ojo), otro, u otra, que tal (s. v. otro), de medio pelo (s. v. pelo), ser de lo que no hay (s. v. ser2), hacer uno de las suyas (s. v. suyo), tal para cual (s. v. tal), o no tener uñas para guitarrero (s. v. uña).

Por último, hay que hablar de un grupo de palabras que presentan la indicación de despectivo en el lugar reservado para la etimología. Todas corresponden a derivados mediante sufijación. Sirvan como ejemplos: cotarro (despect. de coto1), espantajo (despect. de espanto), hermanastro (despect. de hermano), madrastra (despect. de madre), mandracho (despect. de mandra), medicastro (despect. de médico), melgacho (despect. de mielga2) o santucho (despect. de santo).

En resumen, todo esto pone de manifiesto la ausencia de una conciencia, por parte del lexicógrafo, de la necesidad de sistematizar y codificar este tipo de información. El paso siguiente va a ser examinar cómo la marca de despectivo ha llegado a ser lo que es hoy.

\section{Evolución de la marca de despectivo ${ }^{32}$}

Desde el punto de vista de la configuración histórica de la indicación de despectivo en el Diccionario, es necesario hacer constar que la abreviatura despect. no aparece hasta el DRAE-1884. Pero eso no significa que no arranque de más atrás. Hay que te-

32 Los datos que aparecen en este epígrafe los he obtenido mediante el cotejo de los 349 casos del inventario de acepciones con marca de despectivo en el DRAE-1984 y en el DRAE-1992, en cada una de las diecinueve ediciones anteriores y en AUTORIDADES, en orden inverso a la aparición de las ediciones. 0 sea, que no he buscado cómo se han incorporado las acepciones desde AUTORIDADES, sino en qué edición se incorpora la información que actualmente registra el DRAE. No obstante, expongo los resultados siguiendo el orden cronológico, para hacerlos más comprensibles. El número de la acepción se refiere, por ese motivo, al que cada una presenta en el DRAE-1992. 
ner en cuenta que, según mi recuento, ya en AUTORIDADES se encuentran 68 de las 349 acepciones actuales, pero de estas, solo 14 contenían alguna información a este respecto, siempre inserta en la definición: aldeorrio, arrópese con ello (s. v. arropar1), la cara se lo dice (s. v. cara), desbarbado 2, desbragado 2, descamisado 2, destripaterrones, fácil 5, fautor, niño 5, personilla, tal por cual (s. v. tal), buen viaje (s. v. viaje1) y villorrio 33 . Por ejemplo:

Niño. Se llama tambien el que obra con poca reflexion y advertencia: y se suele usar por desprecio.

TAL POR QUAL. Expresion de desprecio, que equivale à cosa de poco mas ó menos, ò indigna.

VillorRio. Población mui corta. Es del estilo familiar, y se usa por desprecio.

En las ediciones posteriores se van produciendo algunas incorporaciones, pero no es hasta el DRAE-1884, con la aparición de la abreviatura, cuando se registra un cambio importante ${ }^{34}$. Se incorporan 23 nuevas acepciones de las 349 actuales, 18 de ellas ya con la indicación de despectivo:

$\begin{array}{llll}\text { artilugio } & \text { cachivache } & \text { cafetucho } & \text { capeja } \\ \text { carruco } & \text { compadraje } & \text { escritorzuelo } & \text { estudiantuelo } \\ \text { farsa } 4 & \text { latinajo 2 } & \text { lloradera } & \text { machote } 2^{35} \\ \text { peine } 8 & \text { polizonte } & \text { recalvastro } & \end{array}$

escardar cebollinos (s. v. cebollino)

lobos de una camada (s. v. lobo)

estar de manga (s. v. manga)

Pero lo que es aún más importante: 49 acepciones que ya estaban en el DRAE1869, toman la marca en el DRAE-1884:

$\begin{array}{llll}\text { amasar } 5 & \text { animalucho } & \text { arrapiezo 2 } & \text { bolchaco } \\ \text { bufonada 2 } & \text { cachivache 2 } & \text { calducho } & \text { camaranchón } \\ \text { camastro } & \text { carnuza } & \text { carricoche 2 } & \text { casuca 2 } \\ \text { casucha } & \text { chuchumeco } & \text { cintajo } & \text { coplón 2 } \\ \text { corrillo } & \text { costurón 2 } & \text { criticastro } & \text { desbragado 2 } \\ \text { estudiantón } & \text { filosofastro } & \text { flacucho } & \text { fraguar 2 } \\ \text { frailuco } & \text { gentecilla 2 } & \text { gentualla } & \text { gentuza }\end{array}$

33 Es interesante observar cómo algunas de estas informaciones aparecen y desaparecen de una determinada acepción del DRAE a lo largo de su historia. Así, desbarbado contiene esta información en AUTORIDADES: 'Suelese usar de esta voz por desprécio del sugéto', la pierde en el DRAE-1780 y en el DRAE-1783, y la recobra en el DRAE-1791; destripaterrones también la pierde en el DRAE-1780, pero no la recupera hasta el DRAE-1936. Vid. más casos en el Apéndice.

34 Al final de este epígrafe figura una tabla en la que se especifica el número de acepciones incorporadas en cada edición. En el Apéndice, cada palabra lleva, al final de la definición, la indicación de la edición en la que se incorpora al $D R A E$, y la edición en la que incluye por primera vez información sobre el uso.

35 La acepción machote 2 estaba en AUTORIDADES, pero desaparece en el DRAE-1791. 


$\begin{array}{llll}\text { herrerón } & \text { latín 2 } & \text { latinajo } & \text { libraco } \\ \text { libracho } & \text { librejo 2 } & \text { manjorrada } & \text { mercachifle 2 } \\ \text { pajarraco } & \text { palabrota } & \text { papelote1 } & \text { papelucho } \\ \text { poblacho } & \text { sugestión 2 } & \text { trapajo } & \text { vejestorio } \\ \text { vulgacho } & & \\ \text { dios los cría y ellos se juntan (s. v. dios) } & \\ \text { otra, u otro, que tal (s. v. otro) } & \\ \text { una tal (s. v. tal) } & & \\ \text { tal para cual (s. v. tal) } & \end{array}$

Tienen que pasar la $13^{\mathrm{a}}$ (DRAE-1899) y la $14^{\mathrm{a}}$ (DRAE-1914) ediciones para que la marca de despectivo registre otro importante aumento. Este se produce en el DRAE1925 , edición en que se incorporan 50 acepciones, de las que 41 ya incluyen esta información:

$\begin{array}{llll}\text { asnejón } & \text { beatuco } & \text { bicharraco } & \text { caldibache } \\ \text { camucha } & \text { carca1 } & \text { carcunda } & \text { catana1 2 } \\ \text { clerigalla } & \text { cleriguicia } & \text { chalanesco } & \text { dómine 2 } \\ \text { empollón } & \text { franchute } & \text { fritanga } & \text { gramatiquear } \\ \text { humoracho } & \text { ingeniosidad 2 } & \text { moñajo } & \text { navajo } \\ \text { papelorio } & \text { pasioncilla 2 } & \text { pitoche } & \text { preceptoril } \\ \text { roto } & \text { sargentona } & \text { señoritingo } & \text { soniquete } \\ \text { suche } 4 & \text { suripanta 2 } & \text { tatarrete } & \text { tiracuero } \\ \text { tontucio } & \text { tragasantos } & \text { tropa } & \text { vidorria 2 } \\ \text { todos somos de la carda (s. v. carda) } & & \\ \text { ser una cosa un carnaval (s. v. carnaval) } & \\ \text { cuatro gatos (s. v. gato1) } & & \\ \text { ser de lo que no hay (s. v. ser2) } & \\ \text { tela de cebolla (s. v. tela) } & \end{array}$

Otras 12 acepciones que ya aparecían en el DRAE-1914 incluyen esta información en el DRAE-1925: discretear, dulzaina2, escopetón, fregona, gabacho 4, gimotear, gramatiquería, ralea 2, saltatumbas, sofista 2 , soflama 4 y tablajero.

A partir de esta edición, se va produciendo un progresivo aumento de las acepciones con este tipo de información, edición a edición:

- DRAE-1936: 25 acepciones se incorporan con la marca de despectivo: barbucha, camarillesco, caminejo, carraca1 3, casaquín, chupatintas, cuartucho, finústico, godo 4, hijuco, homúnculo, hornaza, liberalesco, marrano1, miseriuca, mujeruca, musicastro, palabreja, periodicucho, perote, pesetero 2, pijotero, ricachón, hacer uno de las suyas (s. v. suyo), y tinterillo. Otras 5 toman la marca en esta edición: bajete, destripaterrones, feúco, feúcho y floripondio 2.

- DRAE-1947: 3 acepciones se incorporan con marca de despectivo: abogadil, fondón2 y soldadote.

- DRAE-1956: 10 acepciones se incorporan con marca de despectivo: abogadesco, acromado, aldeón, cavernícola 2, chupacirios, copión1, enchufar 5, retórica 2, sa- 
cristanesco y suficiencia 3. Otras 4 acepciones toman la marca en esta edición: bajonazo, carcamal, halacuerda y retrógrado 2.

- DRAE-1970: 21 acepciones se incorporan con marca de despectivo: amigacho 2, amigote, bordear 4, buchipluma, ser alguien un caso (s. v. caso), chupalámparas, churriguerismo 2, colaboracionista, compadreo, crestudo 2, enchufismo, enchufista, individuo 7, levitín, milico, de morondanga (s. v. morondanga), papelujo, pispajo 3 , plumífero 2, ratón de biblioteca (s. v. ratón), y tipo 9. Una acepción toma la marca en esta edición: maracucho.

- DRAE-1984: 22 acepciones se incorporan con marca de despectivo: adlátere, asuntillo, cachaco 3, capilla 10, capitoste, chillanejo, chirinada, chopa 3, dar o hacer un corte de mangas (s. v. corte), gringaje, hembraje 2, marmota 4, lo de marras (s. v. marras), niñato2, paporreta, paporretear, paternalismo, pisco2 2, runa2, semiculto 2, tutumpote, ventajear 2. Otras 11 acepciones toman la marca en esta edición: antiguaIla 4, babazorro 3, blandengue, borrachín, cambalache 4, cateto 2, flacucho ${ }^{36}$, furcia, gramática parda (s. v. gramática), oportunismo, pigmeo.

Y así se llega a la última edición, en la que se produce la incorporación de 47 nuevas acepciones con marca de despectivo. Este elevado número se debe, especialmente, a los 20 sufijos que aparecen por primera vez en el Diccionario:

$\begin{array}{llll}\text { academizar } & \text {-aco2 } & \text {-acho } & \text {-ajo } \\ \text {-alla } & \text { americanada } & \text { americanada 2 } & \text {-anco } \\ \text {-anga } & \text {-ango } & \text { anteojudo } & \text {-astro } \\ \text { atajo 6 } & \text {-azo } & \text { baranda 2 } & \text { capitanejo 2 } \\ \text { chafirete } & \text { charnego } & \text { cipayo 2 } & \text { cromo 2 2 } \\ \text { cuico 2 } & \text { curángano } & \text {-da } & \text { decimonónico 2 } \\ \text { dominguero 3 } & \text {-ejo } & \text { especular 2 4 } & \text {-ete } \\ \text { grandulón } & \text {-ica } & \text {-ija } & \text {-ijo } \\ \text {-ijón } & \text { joto } & \text { manga 17 } & \text { maqueto } \\ \text { miedica } & \text {-ón 1 } & \text { pinche } & \text { repartija } \\ \text {-rro } & \text {-sco } & \text {-uelo } & \\ \text { tener enchufe (s. v. enchufe) } & & \\ \text { ser un muerto de hambre (s. v. hambre) } & \\ \text { ser un muerto de hambre (s. v. muerto) } & \\ \text { a los ponchazos (s. v. ponchazo) } & \\ \text { El número de acepciones que reciben la marca en el DRAE-1992, aunque ya es- } \\ \text { an en el DRAE-1984, son otras 28: }\end{array}$

36 El caso de flacucho es peculiar, porque se incorpora en el DRAE-1852; tiene marca de familiar en las dos últimas ediciones; la marca de despectivo aparece del DRAE-1884 al DRAE-1956, y del $D R A E-1984$ al DRAE-1992, porque en el DRAE-1884 se define como 'despect. de flaco', y en el $D R A E-1970$ cambia a 'algo flaco', sin indicación alguna. En el DRAE-1984 toma las de despect. y fam.

37 La expresión ser un muerto de hambre se incorpora dos veces: bajo el lema hambre y bajo el lema muerto, y curiosamente con definiciones distintas. 


$\begin{array}{llll}\text { adrede } & \text { agabachar } & \text { artefacto } 3 & \text { bachillerejo } \\ \text { caballejo } & \text { cachupín } & \text { calaña1 } 2 & \text { caricatura } 2 \\ \text { carnaza } 4 & \text { caterva } & \text { chochez } & \text { clan 2 } \\ \text { delgaducho } & \text { dramón } & \text { enchufe 4 } & \text { gabacho } 5 \\ \text { hatajo } 2 & \text { jovenzuelo } & \text { lugarejo } & \text { malejo } \\ \text { medianejo } & \text { melifluamente } & \text { melifluo } 2 & \text { querindango } \\ \text { sotreta } & \text { tipejo } & \\ \text { de medio pelo (s. v. pelo) } & & \\ \text { no tener uñas para guitarrero (s. v. uña) } & \end{array}$

En la tabla siguiente, se encuentran lo datos totales sobre la progresión que sigue la aparición de acepciones y la indicación de despectivo en el $D R A E$, según mi recuento ${ }^{38}$ :

$\begin{array}{cccccccccccc} & \text { Aut. } & 1780 & 1783 & 1791 & 1803 & 1817 & 1822 & 1832 & 1837 & 1843 & 1852 \\ \text { con marca } & 14 & 4 & 0 & 1 & 1 & 2 & 0 & 1 & 0 & 1 & 4 \\ \text { sin marca } & 54 & 4 & 1 & 5 & 8 & 4 & 0 & 4 & 1 & 7 & 3 \\ \begin{array}{c}\text { incorporan } \\ \text { la marca }\end{array} & 0 & 1 & 0 & 4 & 2 & 2 & 0 & 0 & 0 & 0 & 1 \\ & & & & & & & & & & & \\ & 1869 & 1884 & 1899 & 1914 & 1925 & 1936 & 1947 & 1956 & 1970 & 1984 & 1992 \\ \text { con marca } & 2 & 18 & 7 & 5 & 41 & 25 & 3 & 10 & 21 & 22 & 47 \\ \text { sin marca } & 6 & 5 & 0 & 2 & 9 & 3 & 0 & 2 & 3 & 1 & 0 \\ \text { incorporan } & 3 & 4 & 9 & 4 & 0 & 12 & 5 & 0 & 4 & 11 & 28 \\ \text { la marca } & & & & & & & & & & & \end{array}$

Estos datos muestran claramente lo desigual de la evolución de la marca de despectivo, sujeta a los avatares de cada edición, y la importancia de las últimas ediciones en su configuración actual.

\section{CONCLUSIÓN}

Después de lo visto en el análisis del grupo de palabras con indicación de despectivo aquí realizado, del de vulgar (Vid. C. Garriga, 1994), y de los otros grupos cuyos resultados aún no se han publicado, cabe decir que el sistema de marcas de que se dota el Diccionario resulta desigual, y no se encuentran criterios claros que expliquen el alcance de cada una de las notaciones que se utilizan para acotar el uso de una determinada pieza léxica.

38 En primer lugar, se encuentra el número de las acepciones que se incorporan con esta indicación; en segundo lugar, el número de las que se incorporan en cada edición sin la indicación de despectivo y en el DRAE-1992 la tienen; en tercer lugar, el número de acepciones que ya estaban en la edición anterior sin esta indicación, y la toman. 
Como ejemplo de ello puede servir el conjunto de palabras con marca de despectivo, el segundo más importante en el Diccionario por el número de acepciones. En su caracterización, se observa un importante componente morfológico, ya que los derivados con sufijos apreciativos constituyen su núcleo fundamental, junto a una serie de términos de más difícil clasificación cuyo sentido depende en gran medida de determinados aspectos culturales asumidos por la comunidad hablante. La regularidad de bastantes derivados apreciativos, unida a la incorporación de los sufijos en el cuerpo del Diccionario, permite dudar de que la presencia de muchos de estos derivados sea oportuna.

En cuanto al modo como esta información se presenta al usuario, cabe decir que existe una evidente asistematicidad, que permite cuestionar el concepto de marca, que tan frecuentemente utilizamos en lexicografía para referirnos a estas indicaciones, y pensar que lo que el DRAE pretende es solamente abreviar determinadas informaciones, no codificarlas. Porque aunque el metalenguaje empleado para proporcionar esta información al usuario se basa, fundamentalmente, en las abreviaturas, también se utilizan otros medios menos sistemáticos. Como observa P. Corbin ${ }^{39}$, las abreviaturas no constituyen un auténtico metalenguaje definido de forma biunívoca.

La configuración actual del grupo de palabras que tienen la marca de despectivo en el $D R A E-1992$ se entiende mediante un repaso a las diversas ediciones. El hecho de que la abreviatura no aparezca hasta el $D R A E-1884$ condiciona en gran medida el desarrollo de esta información que, por otro lado, sigue las circunstancias de la historia del inventario académico: las ediciones en las que el número de acepciones con esta indicación aumenta apreciablemente son las más importantes en la evolución del Diccionario: $A U$ TORIDADES, DRAE-1884, DRAE-1925 y DRAE-1992, aunque en este siglo haya otras ediciones destacables. El estudio de esta evolución nos muestra que existen dos fases en el desarrollo de esta información tal como la conocemos hoy: una la de incorporar nuevos términos ya convenientemente caracterizados, y la otra la de caracterizar otros términos que ya estaban en ediciones anteriores sin esta información.

Por otro lado, estos problemas de falta de coherencia y sistematicidad no son exclusivos del Diccionario académico, sino de la lexicografía en general. Podríamos suscribir para la lexicografía del s. XX las palabras de M. Glatigny ${ }^{40}$ a propósito de los diccionarios franceses de la Ilustración, al referirse a la incertidumbre que existía sobre las categorías, los criterios y la formulación, el papel y el lugar que corresponde a las marcas de uso en el discurso lexicográfico.

Pero todos estos problemas no deben hacer desistir al lexicógrafo de marcar estos hechos en el Diccionario. En el prólogo de Le grand Robert de la langue française, A. Rey ${ }^{41}$ consideraba que, a pesar de las dificultades, el método de acotar el uso de una palabra es indispensable para el perfeccionamiento de los diccionarios, y comparaba la importancia de este tipo de información a la de la información semántica o sintáctica. Refiriéndose a los diccionarios para la enseñanza de la lengua extranjera, F. J. Hausmannn ${ }^{42}$

40 Vid. M. Glatigny (1990), p. 11.

41 Vid. A. REY (1985), p. XLI.

42 Vid. F. J. Hausmann (1990), p. 1.387. 
se refería a estos aspectos con las siguientes palabras: "marquer abondamment. Dans le doute, marquer plutôt que d'y renoncer, surtout en ce qui concerne les niveaux de langue et la frequence". Sin duda, perfeccionar la información sobre el uso es uno de los retos de la lexicografía actual.

\section{BIBLIOGRAFÍA DE REFERENCIA}

BosQue, IGnacio (1982): "Sobre la teoría de la definición lexicográfica”, Verba, 9, pp. 105-123. CASARES, JULIO (1950): Introducción a la lexicografía moderna, Madrid, CSIC, 1969.

CORBIN, PIERRE (1989): "Les marques stylistiques / diastratiques dans le dictionnaire monolingue", en Franz Josef Hausmann y otros, eds., Wörterbücher, Dictionaries, Dictionnaires. Ein Internationales Handbuch zur Lexikographie, vol. I, Berlín - New York, W. de Gruyter, pp. 673-680.

CORBIN, PIERRE (1991): "La lexicographie moderne: contrepoint. Réflexions sur la contribution de Josette Rey-Debove", Travaux de Linguistique, 23, pp. 161-169.

ETTINGER, STEFAN (1982): "La variación lingüística en lexicografía”, en Günther Haensch y otros, La lexicografía: de la lingüistica teórica a la lexicografía práctica, Madrid, Gredos, pp. 359-394.

GarRIGA, CeClilo (1994): “La marca de vulgar en el DRAE: de Autoridades a 1992", Sintagma, 6, pp. 5-13.

Gemmingen, BarbaRA von (1990): "Recherches sur les marques d'usage dans le Tesoro de las dos lengvas francesa y española de Cesar Oudin (1607)", en Michel Glatigny (coord.), Lexique: Les marques d'usages dans les dictionnaires (XVIIe-XVIIle siècles), Lille, Presses Universitaires, pp. 31-41.

GiRARDIN, Chantal (1987): "Système de marques et connotations sociales dans quelques dictionnaires culturels français", Lexicographica, 3, pp. 76-102.

Glatigny, Michel (1990): "L'importance des marques d'usage", en Michel Glatigny (coord.), Lexique: Les marques d'usages dans les dictionnaires (XVIIe - XVIIIe siècles), Lille, Presses Universitaires, pp. 7-16.

HaUsmann, Franz JoSef (1989): "Die Markierung im allgemeinen einsprachigen Wörterbuch: eine Übersicht", en Franz Josef Hausmann y otros, eds., Wörterbücher, Dictionaries, Dictionnaires. Ein Internationales Handbuch zur Lexikographie, vol. I, Berlín-New York, W. de Gruyter, pp. 649-657.

Hausmann, Franz Josef (1990): “Les dictionnaires pour l'enseignement de la langue étrangère: français", en Franz Josef Hausmann y otros, eds, Wörterbücher, Dictionaries, Dictionnaires. Ein Internationales Handbuch zur Lexikographie, vol. II, Berlín-New York, W. de Gruyter, pp. 1386-1390.

Hausmann, Franz Josef y otros, eds., (1989-1991): Wörterbücher, Dictionaries, Dictionnaires. Ein Internationales Handbuch zur Lexikographie, 3 vol. , Berlín-New York, W. de Gruyter.

HERNÁNDEZ, HUMBerTo (1990): "Hacia un modelo de diccionario monolingüe del español para extranjeros", Actas del I Congreso Nacional de ASELE, Granada, Universidad, pp. 159-166. 
ImBS, PAUL (1969): “Les niveaux de langue dans le dictionnaire”, Le français dans le Monde, 69, pp. 51-60.

Landau, Sidney (1984): “Usages”, Dictionaries: the Art and Craft of Lexicography, Cambridge, Cambridge University Press, 1991, pp. 174-225.

LanG, Mervyn F. (1990): Formación de palabras en español, Madrid, Cátedra, 1992.

LesselaAR, P. A. (1988): “Les marques familier et populaire envisagées des points de vue lexicologique et lexicographique", Cahiers de Lexicologie, 2, pp. 91-106.

Moliner, María (1966): Diccionario de uso del español, Madrid, Gredos.

REY, Alain (1985): Le grand Robert de la langue française, Paris, Le Robert.

REY, ALAIN (1990): "Les marques d'usages et leur mise en place dans les dictionnaires du XVIIè siècle: le cas Furetière", en Michel Glatigny, coord., Lexique: Les marques d'usages dans les dictionnaires (XVIIe-XVIIIe siècles), Lille, Presses Universitaires, pp. 17-29.

Rey, Alain y Josette Rey-Debove, dir., (1990): Petit Robert, Paris, Le Robert.

REY-DEBOVE, JoSETTE (1971): “Incertitudes quant à l'homogénéité du lexique", Étude linguistique et sémiotique des dictionnaires français contemporains, The Hague-Paris, Mouton, pp. 91-99.

Rey-Debove, JosetTe (1989): "La métalangue lexicographique: formes et fonctions en lexicographie monolingue", en Franz Josef Hausmann y otros, eds., Wörterbücher, Dictionaries, Dictionnaires. Ein Internationales Handbuch zur Lexikographie, vol. I, Berlín - New York, W. de Gruyter, pp. 305-312.

Summers, Della, dir., (1992): Dictionary of Contemporary English, Harlow, Longman, 15a reimpresión, [1987].

SVENSÉN, Bo (1987): "Subjects Field and Register Labels", Practical Lexicography: Principles and Methods of Dictionary-Making, Oxford-New York, Oxford University Press, 1993, pp. 181-188.

Ullmann, StePhen (1962): Semántica, introducción a la ciencia del significado, Madrid, Taurus, 1992.

Zgusta, Ladislav (1971): "Variation in laguage", Manual of lexicography, The Hague-Paris, Mouton, pp. 164-196.

DiCCIONARIOS DE LA ACADEMIA

Autoridades: Real ACADEmia Española (1726-1739): Diccionario de la lengua castellana, Madrid, Francisco del Hierro. Facsímil en Madrid, Gredos, 1984.

DRAE-1780: Real Academia Española (1780): Diccionario de la lengua castellana, Madrid, J. Ibarra. Facsímil en Madrid, Espasa-Calpe, 1991.

DRAE-1783: Real ACADEmia Española (1783): Diccionario de la lengua castellana, Madrid, J. Ibarra, $2^{\mathrm{a}}$ ed.

DRAE-1791: Real Academia Española (1791): Diccionario de la lengua castellana, Madrid, Vda. de J. Ibarra, $3^{\text {a }}$ ed. 
DRAE-1803: ReAl ACADEMIA Española (1803): Diccionario de la lengua castellana, Madrid, Vda. de J. Ibarra, $4^{\text {a }}$ ed.

DRAE-1817: Real Academia Española (1817): Diccionario de la lengua castellana, Madrid, Imprenta Real, $5^{\mathrm{a}}$ ed.

DRAE-1822: ACADEMIA ESPAÑOLA (1822): Diccionario de la lengua castellana, Madrid, Imprenta Nacional, $6^{\mathrm{a}}$ ed.

DRAE-1832: ACADEMIA ESPAÑola (1832): Diccionario de la lengua castellana, Madrid, Imprenta Real, $7^{\mathrm{a}}$ ed.

DRAE-1837: ACADEMIA ESPAÑOLA (1837): Diccionario de la lengua castellana, Madrid, Imprenta Nacional, $8^{\mathrm{a}}$ ed.

DRAE-1843: ACADEMIA EsPañola (1843): Diccionario de la lengua castellana, Madrid, F. Ma Fernández, $9^{\mathrm{a}}$ ed.

DRAE-1852: ACADEMIA EsPaÑola (1852): Diccionario de la lengua castellana, Madrid, Imprenta Nacional, $10^{\mathrm{a}}$ ed.

DRAE-1869: ACADEMIA Española (1869): Diccionario de la lengua castellana, Madrid, Manuel Rivadeneyra, $11^{\text {a }}$ ed.

DRAE-1884: Real ACAdemia Española (1884): Diccionario de la lengua castellana, Madrid, Gregorio Hernando, $12^{\mathrm{a}}$ ed.

DRAE-1899: Real ACAdemia Española (1899): Diccionario de la lengua castellana, Madrid, Hernando y Cía., $13^{\mathrm{a}}$ ed.

DRAE-1914: Real ACademia Española (1814): Diccionario de la lengua castellana, Madrid, Sucesores de Hernando, $14^{\mathrm{a}}$ ed.

DRAE-1925: ReAl ACAdemia Española (1925): Diccionario de la lengua española, Madrid, Calpe, $15^{\mathrm{a}}$ ed.

DRAE-1936: Academia Española (1936),:Diccionario de la lengua española, Madrid, EspasaCalpe, $16^{\mathrm{a}}$ ed.

DRAE-1947: ReAl ACADEMIA Española (1947): Diccionario de la lengua española, Madrid, EspasaCalpe, $17^{\mathrm{a}}$ ed.

DRAE-1956: Real Academia Española (1956): Diccionario de la lengua española, Madrid, EspasaCalpe, $18^{\mathrm{a}}$ ed.

DRAE-1970: Real Academia Española (1970): Diccionario de la lengua española, Madrid, EspasaCalpe, $19^{\mathrm{a}}$ ed.

DRAE-1984: Real Academia Española (1984): Diccionario de la lengua española, Madrid, EspasaCalpe, $20^{\mathrm{a}}$ ed.

DRAE-1992: Real Academia Española (1992): Diccionario de la lengua española, Madrid, EspasaCalpe, $21^{\text {a }}$ ed. 


\section{APÉNDICE}

En este apéndice se pueden encontrar las 349 acepciones que en el DRAE-1992 aparecen con alguna indicación que haga referencia a la marca de despectivo, con la definición íntegra, salvo la indicación de la categoría gramatical. Entre paréntesis aparecen informaciones complementarias sobre cambios que la definición ha experimentado en alguna de las ediciones del $D R A E^{43}$. Entre corchetes se halla la información sobre el año de la edición en que la acepción se incorpora al $D R A E$, y el de la edición en que recibe la marca de despectivo ${ }^{44}$. En el interior de los corchetes y los paréntesis utilizo las siguientes abreviaturas:
Aut.: Diccionario de Autoridades.
bax.: marca de baxo.
desp.: marca de despectivo.
fam.: marca de familiar.
inc.: año de la edición en que la acepción se incorpora al DRAE.
joc.: marca de jocoso.
vulg.: marca de vulgar.

abogadesco, ca. Perteneciente o relativo al abogado o a su profesión. Ú. por lo común en sent. despect. [inc. y desp.: 1956]

abogadil. despect. Perteneciente a los abogados. No es despect. en Costa Rica. [inc. y desp.: 1947]

academizar. Proporcionar o atribuir carácter académico a una obra o actuación. Ú. t. en sent. fig. y con frecuencia peyorativo. [inc. y desp.: 1992]

-aco2, ca. suf. despectivo: libraco. [inc. y desp.: 1992]

acromado, da. Dícese de lo que se asemeja a un cromo, estampa y especialmente de las obras pictóricas. Se usa generalmente en sentido peyorativo. (1984. Tómase por lo común a mala parte.) [inc. y desp.: 1956]

-acho, -acha. suf. de sustantivos y adjetivos

con valor despectivo: poblacHO, ГícACHA.

Combinado con -ar toma la forma -aracho: dichARACHO, vivaraCHO (sic). [inc. y desp.: 1992]

adlátere. despect. Persona subordinada a otra, de la que parece inseparable. (1984. Tómase con frecuencia en mala parte.) [inc. y desp.: 1984]

adrede. De propósito, con deliberada intención. Se usa muy a menudo con matiz peyorativo. [inc.: Aut // desp.: 1992]

advenedizo, za. 2. despect. Dícese de la persona que, sin empleo u oficio, va a estable-

43 Téngase en cuenta que el cotejo de las ediciones se ha hecho desde el DRAE-1992 hacia atrás, por lo que se pueden encontrar comentarios como el siguiente: "bajonazo. despect. Taurom. Estocada excesivamente baja. (1947. Golletazo.) [inc.: 1914 // desp.: 1956]". Significa que en la edición del DRAE-1947 es la última en que aparece la definición 'golletazo', antes de ser como en la actualidad.

44 Un comentario como [inc.: Aut // desp.: 1780] significa que esa acepción se incorpora al DRAE en AUTORIDADES pero que no recibe la marca de despectivo hasta el DRAE-1780. El comentario [inc. y desp.: 1956] significa que la acepción se incorpora, ya con marca de despectivo, en el DRAE-1956. Un comentario como [inc.: Aut // vulg.: Aut // fam.: 1780 a 1992 // desp.: Aut a 1992] significa que la acepción se incorpora en AUTORIDADES, ya con la marca de vulgar, en el DRAE-1780 la pierde, y toma la de familiar que mantiene hasta el DRAE-1992; la marca de despectivo la tiene desde AUTORIDADES hasta hoy. 
cerse en un país o en un pueblo. (Aut a 1884. Por menosprecio...) [inc.: Aut // desp.: 1780]

agabachar. despect. Hacer que una persona imite a los gabachos, o sus costumbres, lenguaje, etc. [inc.: 1925 // desp.: 1992]

-ajo, ja. suf. de sustantivos y adjetivos con valor entre despectivo y diminutivo: tendAJo, migaja, escobajo, pequeñajo. Puede combinarse con -ar: espumaRAJo; con -arro: pintARRAJO; a veces toma la forma -strajo: comisTRAJO; estas combinaciones tienen valor despectivo. [inc. y desp.: 1992]

aldeón. aum. despect. de aldea. [inc. y desp.: 1956]

aldeorrio o aldeorro. despect. Lugar muy pequeño, pobre o falto de cultura. (Aut a 1852. Por desprecio...) [inc. y desp.: Aut] alquiladizo. p. us. Que se alquila. Decíase especialmente del que trabajaba por cuenta de otro y, despectivamente, del que servía en la guerra a cambio de una paga. (1984. Apl. a pers., es despect.) (1780 a 1869. En lo antiguo, se halla aplicado por desprecio...) [inc. y desp.: 1780]

alquilón. despect. alquiladizo. Apl. a pers. (1780 a 1869. Dícese por desprecio de las personas que se alquilan para alguna cosa.) [inc.: 1780 // bax.: 1780 a 1791 // desp.: 1780] -alla. suf. de valor entre colectivo y despectivo: morralla, canalla. [inc. y desp.: 1992] amasar. 5. fig. y fam. Disponer bien las cosas para el logro de lo que se intenta. Se usa generalmente en sentido peyorativo. (1984. en mala parte.) [inc.: Aut // fam. y desp.: 1884]

americanada. despect. Película típicamente estadounidense. [inc. y desp.: 1992]

americanada. 2. despect. Dicho o hecho propio de los angloamericanos. [inc. y desp.: 1992] amigacho. 2. despect. amigote, compañero de francachelas. [inc. y desp.: 1970] amigote. despect. Compañero habitual de francachelas y diversiones (1984. poco recomendables). [inc. y desp.: 1970] -anco, ca. suf. de valor generalmente despectivo: potrancA, lunANCo. [inc. y desp.: 1992] anchura. 6. fig. Libertad, soltura, desahogo.
Suele usarse en sentido peyorativo. (1817 a 1984. en mal sentido.) [inc. y desp.: 1817] andrajo. 3. fig. y despect. Persona o cosa muy despreciable. (1780 a 1869. por desprecio.) [inc.: 1780 // fam.: 1803 a $1884 / /$ desp.: 1780 a 1869, 1899 a 1992]

-anga. suf. de sustantivos, con valor generalmente despectivo: bullanga, fritanGA. [inc. y desp.: 1992]

-ango, ga. suf. despect. de sustantivos y adjetivos. Fritanga, maturranga, pendanga. [inc. y desp.: 1992]

animalucho. despect. Animal de figura desagradable. [inc.: 1783 // desp.: 1884]

anteojudo. despect. Argent., Chile, Guat. Que usa anteojos. [inc. y desp.: 1992]

antigualla. 4. despect. Mueble, traje, adorno o cosa semejante que ya no está de moda. [inc.: 1869 // desp.: 1984]

arrapiezo. 2. fig. y despect. Persona pequeña, de corta edad o humilde condición. (1780 a 1817. Se dice de cualquiera hombre o muger pequeña y despreciable...) [inc.: Aut // fam.: 1852 a 1869 // desp.: 1884]

arropar1. II arrópese con ello. fr. fam. con que se rechaza despectivamente lo que a uno le dan. [...] Bien se puede ARROPAR CON ELLO. (1780 a 1884. fr. fam. con que se desprecia...) (Aut. Frase vulgar con que se hace desprecio...) [inc.: Aut // vulg.: Aut // fam.: 1780 a 1992 // desp.: Aut a 1992]

artefacto. 3. despect. Máquina, mueble, y en general, cualquier objeto de cierto tamaño. (1984. Armatoste, máquina, mueble, etc., tosco, pesado o mal hecho.) [inc.: 1984 // desp.: 1992]

artería. Amaño, astucia que se emplea para algún fin. Hoy se toma siempre en mal sentido. [inc.: Aut // desp.: 1869]

artero, ra. Mañoso, astuto. Hoy se toma siempre en mal sentido. [inc.: Aut // desp.: 1869]

artilugio. Mecanismo, artefacto, sobre todo si es de cierta complicación; suele usarse con sentido despectivo. (1947. despect. Aparato o mecanismo artificioso, pero de poca importancia y duración.) [inc. y desp.: 1884] 
asnejón. aum. y despect. asno, persona torpe. [inc. y desp.: 1925]

-astro, tra. suf. de sustantivos, con significado despectivo: musicastro, politicaSTRO, madrASTRA. A veces toma la forma -astre: piIlASTRE. [inc. y desp.: 1992]

asuntillo. d. de asunto, negocio. Suele emplearse con diversos matices, irónico, despectivo, minorativo, etc. [inc. y desp.: 1984]

atajo. 6. despect. hatajo, grupo de personas o cosas. [inc. y desp.: 1992]

-azo, za. suf. de valor aumentativo: perrazo, manAzA, o despectivo: aceitazo. [...]. [inc. y desp.: 1992]

babazorro, rra. 3. Natural de Álava. Ú. con sent. despect. [inc.: 1925 // desp.: 1984]

bachillerejo, ja. despect. de bachiller2. (1780 a 1791. d. p. us. de "bachiller". El que habla demasiado. Es voz de desprecio.) [inc.: 1780 // desp.: 1780 a 1791, 1992]

bajete. d. despect. de bajo. [inc.: Aut // desp.: 1936]

bajonazo. despect. Taurom. Estocada excesivamente baja. (1947. Golletazo.) [inc.: 1914 // desp.: 1956]

baranda2. vulg. despect. Deixis para referirse a una persona. [inc., desp. y vulg.: 1992]

barbucha. despect. de barba. [inc. y desp.: 1936]

beatuco. despect. de beato. [inc. y desp.: 1925] bicharraco. despect. de bicho. [inc. y desp.: 1925]

blandengue. despect. Blando, con blandura poco grata. [inc.: 1925 // desp.: 1984]

bolchaco. fam. y despect. Ar. bolchaca. (Aut.

Es voz usada en Aragón, pero solamente por el vulgo.) [inc.: Aut // bax.: 1780 a 1803 // fam.: 1817 a 1992 // desp.: 1884] bordear. 4 . Tratándose de condiciones o cualidades morales o intelectuales, aproximarse a un grado o estado de ellas. Ú. m. en sentido peyorativo: Una exaltación que BORDEA la locura; chistes chocarreros que BORDEAN la indecencia. [inc. y desp.: 1970]

borrachín, na. Dícese de la persona que tiene el hábito de embriagarse. Ú. frecuentemente con valores afectivos, ya atenuadores, ya despectivos. [inc.: 1925 // desp.: 1984] buchipluma. despect. Ant. Dícese de la persona que promete y no cumple, o de quien se las echa de algo sin poder hacerlo. [inc. y desp.: 1970]

bufonada. 2. Chanza satírica. Se usa generalmente en sentido peyorativo. Con buena BUFONADA te vienes. (1984. Tómase generalmente en mala parte.) [inc.: Aut // desp.: 1884]

caballejo. d. o despect. de caballo. [inc.: Aut // desp.: 1992]

cachaco, ca. 3. despect. Perú. Policía; militar en general. [inc. y desp.: 1984]

cachimbo. 3. despect. Perú. Guardia nacional. [inc. y desp.: 1899]

cachivache. despect. Vasija, utensilio, trebejo.

[inc., fam. y desp.: 1884]

cachivache. 2 . despect. Cosa de este género, rota o arrinconada por inútil. [inc.: Aut // desp.: 1884]

cachupín, na. despect. fam. Amér. Español establecido en América. (1984. Mote que se aplica al español que pasa a la América septentrional y se establece en ella.) [inc.: Aut // desp.: 1992]

cafetucho. despect. de café, local donde se toma esta bebida. [inc. y desp.: 1884]

cagatinta o cagatintas. fam. despect. oficinista. (1891. Apodo que se aplica a los que tienen empleo de pluma.) [inc. 1891, 1852 a 1992 // fam.: 1852 a 1992 // desp.: 1852] calaña1. 2. fig. Índole, calidad, naturaleza de una persona o cosa. Ser de buena, o mala, CALAÑA. Ú. m. en sent. despect. [inc.: Aut // desp.: 1992]

caldibache. despect. calducho. [inc. y desp.: 1925]

calducho. despect. Caldo de poca sustancia o mal sazonado. [inc.: Aut // vulg.: Aut // bax.: 1780 a 1803 // desp.: 1884]

callejuela. d. despect. de calleja1, calle estrecha. [inc.: Aut // desp.: 1899]

camaranchón. despect. Desván de la casa, o lo más alto de ella, donde se suelen guardar trastos viejos. [inc.: Aut // desp.: 1884] camarillesco, ca. despect. Propio de una camarilla. [inc. y desp.: 1936]

camastro. despect. Lecho pobre y sin aliño. [inc.: Aut // desp.: 1884] 
cambalache. 4. despect. Trueque de diversos objetos, valiosos o no. Ú. t. c. despect. [inc.: Aut // fam.: Aut a 1970 // desp.: 1984] caminejo. d. despect. de camino. [inc. y desp.: 1936]

camucha. fam. despect. de cama1, armazón para dormir. [inc., fam. y desp.: 1925]

capeja. despect. Capa pequeña o mala. [inc. y desp.: 1884]

capilla. 10. fig. Pequeño grupo de adictos a una persona o a una idea. Ú. m. en d., y por lo común en sent. despect. [inc. y desp.: 1984] capitanejo. 2. p. us. Argent. Caudillo local subordinado a otro. Ú. m. en sent. despect. [inc. y desp.: 1992]

capitoste. Persona con influencia, mando, etc. Ú. con sent. despect. [inc. y desp.: 1984]

cara. II la cara se lo dice. expr. fam. con que se denota la conformidad entre las inclinaciones o costumbres de una persona y su semblante. Ú. generalmente en sentido peyorativo. (1780 a 1984. Tómase por lo común en mala parte.) (Aut. se usa en contrario.) [inc. y desp.: Aut]

carca1. despect. carcunda. (1899. Carlista, y por ext., persona de ideas retrógradas.) [inc. y desp.: 1925]

carcamal. fam. Persona decrépita y achacosa. Suele tener valor despectivo. [inc.: 1780 // fam.: 1780 a 1947 // desp.: 1956]

carcunda. despect. carlista, y por ext., persona de actitudes retrógradas. (1956. Carca.) [inc. y desp.: 1925]

carda. II todos somos de la carda. fr. fig. y despect. Todos somos de la misma condición o clase. [inc. y desp.: 1925]

caricatura. 2. Obra de arte que ridiculiza o toma en broma el modelo que tiene por objeto. Ú. t. en sent. despect. para referirse a las obras que no alcanzan a ser aquello que pretenden. (1984. Obra de arte en que claramente o...) [inc.: 1832 // desp.: 1992] carnaval. II ser una cosa un carnaval. 2. fig. y despect. Dícese del conjunto de informalidades y fingimientos que se reprochan en una reunión o en el trato de un negocio. [inc. y desp.: 1925] carnaza. 4. fig. despect. Víctima inocente, que carga sobre sí el riesgo o el daño que incumbe a otro. Servir alguien de CARNAZA, echar a alguien de CARNAZA. (1984. El que sufre el daño a que otro le arroja para librarse de él.) [inc.: 1925 // desp.: 1992]

carnuza. despect. Carne basta o excesiva, que produce hastío. [inc.: 1817 // desp.: 1884]

carraca1. 2. despect. Barco viejo o tardo en navegar (1984., y por extensión, cualquier artefacto deteriorado y caduco.) [inc.: Aut // desp.: 1899]

carraca1. 3. despect. Por ext., cualquier artefacto deteriorado y caduco. (1984. en la acepc. ant.) [inc. y desp.: 1936]

carricoche. 2. despect. Coche viejo o de mala figura. [inc.: Aut // desp.: 1884]

carruco. despect. de carro1. [inc. y desp.: 1884]

casaquín. d. despect. de casaca, vestidura. [inc. y desp.: 1936]

caso1. II ser alguien un caso. fr. fig. y fam. con que se designa a la persona que se distingue de las demás para bien o para mal. Ú. m. en sentido peyorativo. [inc., fam. y desp.: 1970]

casuca. 2. despect. casucha. [inc.: 1843 // desp.: 1884]

casucha, cho. despect. Casa pequeña y mal construida. [inc.: $1780 / /$ fam.: 1780 a 1869 // desp.: 1884]

catana 1. 2. despect. Chile. Sable, en especial el largo y viejo, que usaban los policías. [inc. y desp.: 1925]

caterva. Multitud de personas o cosas consideradas en grupo, pero sin concierto, o de poco valor e importancia. Ú. t. en sent. peyorativo. [inc.: Aut // desp.: 1992]

cateto2, ta. despect. Lugareño, palurdo. [inc.: 1936 // desp.: 1984]

cavernícola. 2. despect. fig. y fam. retrógrado, partidario de instituciones políticas que se consideran anticuadas. [inc., fam. y desp.: 1956]

cebollino. II escardar cebollinos. fr. fig. y fam. No hacer nada de provecho. Ú. en sent. despect. con los verbos enviar, ir, estar, etc., y 
más generalmente para echar a alguno en hora mala. [inc., fam. y desp.: 1884]

chafirete, ta. despect. Méj. chofer. [inc. y desp.: 1992]

chalanesco, ca. despect. Propio de chalanes, tratantes de bestias. [inc. y desp.: 1925]

charnego, ga. despect. En Cataluña, inmigrante de otra región española de habla no catalana. [inc. y desp.: 1992]

chillanejo, ja. despect. chillanense. [inc. y desp.: 1984]

chirinada. Argent., Par. y Urug. Asonada inútil, motín frustrado. Ú. t. en sent. despect. [inc. y desp.: 1984]

chochez. despect. Cualidad de chocho; condición de la persona caracterizada por el declive de sus facultades mentales, generalmente a causa de la edad. (1984. Calidad de chocho.) (1869. Debilidad del juicio y de la memoria por la edad.) [inc.: Aut // desp.: 1992]

chopa3. Sto. Dom. Sirvienta, criada. Ú. m. en sent. despect. [inc. y desp.: 1984]

chorroborro. fig. y despect. aluvión de cosas inútiles. [inc. y desp.: 1899]

chuchumeco. despect. Apodo con que se zahiere al hombre ruin. [inc.: Aut // vulg.: Aut // desp.: 1884]

chupacirios. despect. beato, hombre que frecuenta mucho los templos. [inc. y desp.: 1956]

chupalámparas. despect. Persona beata o santurrona, chupacirios. [inc. y desp.: 1970]

chupatintas. despect. Oficinista de poca categoría. [inc. y desp.: 1936]

churriguerismo2. Por ext., denota a veces en sent. despect., la ornamentación exagerada en general. (1984.: $1^{\text {a }}$ acep.) [inc. y desp.: 1970]

cintajo. despect. de cinta. (1869. Cinta despreciable, ridícula o ajada.) [inc.: 1843 // desp.: 1884]

cipayo. 2. despect. secuaz a sueldo. [inc. y desp.: 1992]

clan. 2. despect. Grupo restringido de personas unidas por vínculos e intereses comunes. (1984. Por ext., grupo de personas unidas por un interés común). (1936, por extensión se aplica a otras formas de agrupación humana.) [inc.: 1925 // desp.: 1992] clarucho, cha. despect. Aplícase a la sustancia desleída en cantidad excesiva de agua u otro líquido. [inc.: 1869 // fam.: 1884 a 1914 // desp.: 1869]

clerigalla. despect. clero. [inc. y desp.: 1925] cleriguicia. despect. clerecía. [inc. y desp.: 1925] cojitranco. despect. cojo. Dícese del que cojea de forma llamativa, dando pasos largos o trancos. (1984. Dícese del cojo travieso...) (1817 a 1852. se aplica por desprecio...) (1780 a 1803. "coxitranco". Apodo...) [inc.: Aut // desp.: 1817]

colaboracionista. En sentido despectivo, el que presta su colaboración a un régimen político que la mayoría de los ciudadanos considera antipatriótico. [inc. y desp.: 1970]

comedión. despect. aum. de comedia. (1843 a

1869. Dícese vulgarmente por desprecio.) [inc.: 1843 // vulg.: 1843 a 1869 // desp.: 1843]

compadraje. Unión o concierto de varias personas para alabarse o ayudarse mutuamente. Ú. en sent. peyorativo. (1984. En mala parte.) [inc. y desp.: 1884]

compadreo. Compadraje, unión de personas para ayudarse mutuamente. Suele tener valor despectivo. [inc. y desp.: 1970]

copión1. aum. despect. de copia. [inc. y desp.: 1956]

coplón, na. 2.. despect. Mala composición poética. [inc.: Aut // desp.: 1884]

corrillo. Corro donde se juntan algunas personas a discutir y hablar, separados del resto de la gente. En pl., se usa generalmente en sentido peyorativo. (1984. Tómase por lo común en mala parte.) [inc.: Aut // desp.: 1884]

corte. II dar o hacer un corte de mangas. fr. fig. y vulg. Ademán de significado obsceno $\mathrm{y}$ despectivo que se hace con la mano, extendiendo el dedo corazón entre el índice y el anular doblados. A la vez se levanta el brazo y se golpea en él con la otra mano. [inc., vulg. y desp.: 1984]

costurón. 2. despect. Costura grosera. [inc.: Aut // desp.: 1884] 
crestudo, da. 2. fig. despect. Orgulloso, arrogante. [inc. y desp.: 1970]

criticastro. despect. El que sin apoyo ni fundamento ni doctrina censura y satiriza las obras de ingenio. [inc.: 1832 // desp.: 1884] cromo2. 2. En sent. despect., dibujo o pintura de colores chillones y escasa calidad. [inc. y desp.: 1992]

cuartucho. despect. Vivienda o cuarto malo y pequeño. [inc. y desp.: 1936]

cuchara. II de cuchara. loc. despect. que se aplicaba a los jefes y oficiales del ejército procedentes de la clase de tropa. [inc.: 1970 // vulg.: 1970 a 1984 // desp.: 1992] cuico. 2. despect. Méj. Guarda o agente de policía. [inc. y desp.: 1992]

curángano. despect. cura, sacerdote. [inc. y desp.: 1992]

-da. suf. de sustantivos derivados de otros sustantivos o de verbos. [...] La variante -ada forma derivados que significan: [...] acción, a veces con matiz peyorativo: alcaldADA, zanCADA, trastaDA. [...] [inc. y desp.: 1992]

decimonónico, ca. 2. despect. Anticuado, pasado de moda. [inc. y desp.: 1992]

delgaducho, cha. despect. Delgado. (1984. Algo delgado.) [inc.: 1925 // desp.: 1992] desbarbado, da. 2. Que carece de barba. Ú. a veces en sent. despect. (1791 a 1817. Se suele usar esta voz por desprecio del sujeto a quien se aplica.) (Aut. Suelese usar de esta voz por desprécio del sugeto.) [inc.: Aut // desp.: Aut, 1791 a 1992]

desbragado, da. 2. fig. y despect. descamisado, muy pobre. (1791 a 1817. Y así se dice por injuria: es un desbragado.) (Aut a 1783. Sin bragas. Suélese decir a alguno por desprecio, y para motejarle de pobretón...) [inc.: Aut // desp.: Aut a 1783, 1884 a 1992]

descamisado, da. 2. fig. y despect. Muy pobre, desharrapado. (1803 a 1869. Se aplica por desprecio al que es muy pobre.) (1791. adj. que por desprecio suele aplicarse al que es muy pobre.) (Aut. Es voz con que comúnmente se desprecia...) [inc.: Aut // desp.: Aut, 1791 a 1992]

destripaterrones. fig., fam. y despect. Gañán o jornalero que cava o ara la tierra. (1780. en destripar.) (Aut. Se usa regularmente de este nombre para zaherir o despreciar a alguno.) [inc.: Aut // fam.: 1791 a 1803 // desp.: Aut, 1936 a 1992]

dios. II Dios los cría y ellos se juntan. expr. fig. y fam. con que se da a entender que los que son semejantes en las inclinaciones $\mathrm{y}$ en el ingenio se buscan unos a otros. Ú. generalmente en sentido peyorativo. (1984. en mala parte.) [inc.: $1817 / /$ desp.: 1884]

discretear. Ostentar discreción, hacerse el discreto. Ú. c. despect. (1791 a 1914. Ú. comúnmente / ordinariamente por burla.) [inc.: Aut // desp.: 1925]

dómine. 2. despect. Persona que, sin mérito para ello, adopta el tono de maestro. [inc. y desp.: 1925]

dominguero, ra. 3. despect. Dícese del conductor inexperto que solo utiliza el automóvil los domingos y días festivos. [inc. y desp.: 1992]

dramón. Drama de tintes muy cargados. Ú. m. en sent. despect. (1984. Drama terrorífico y malo.) [inc.: 1936 // desp.: 1992]

dulzaina2. despect. Cantidad abundante de dulce malo. [inc.: $1791 / /$ fam.: 1791 a 1914 // desp.: 1925]

-ejo, ja. suf., entre diminutivo y despectivo, de sustantivos y adjetivos: animaleJo, diablEJo, medianEJo. En algunas palabras no se conserva el valor diminutivo o despectivo: festEJO. [inc. y desp.: 1992]

empatar. II empatársela a uno. fr. fam. Igualarlo en una acción sobresaliente o extraordinaria. Se usa también en sentido peyorativo. (1791 a 1984. Tómase / dícese también en mala parte.) [inc. y desp.: 1791]

empollón, na. Dícese, despectivamente, del estudiante que prepara mucho sus lecciones, $y$ se distingue más por la aplicación que por el talento. [inc. y desp.: 1925]

enchufar. 5. fam. despect. Colocar en un cargo o destino a quien no tiene méritos para ello, por amistad o por influencia política. [inc., fam. y desp.: 1956] 
enchufe. 4. fig. y fam. despect. Cargo o destino que se obtiene sin méritos, por amistad o por influencia política. Se usa por lo común hablando del que se acumula sobre el empleo profesional. [inc.: 1936 // desp.: 1992] enchufe. II tener enchufe. fr. fam. y a veces despect. Tener influencia ante una autoridad para conseguir de ella algún favor. [inc. y desp.: 1992]

enchufismo. despect. Corruptela política y social que favorece a los enchufistas. [inc. y desp.: 1970]

enchufista. fam. despect. Persona que disfruta de varios enchufes o sinecuras. [inc., fam. y desp.: 1970]

escopetón. aum. de escopeta. Ú. t. c. despect. [inc.: $1791 / /$ desp.: 1925]

escritorzuelo, la. d. despect. de escritor. [inc. y desp.: 1884]

escuderón. despect. El que intenta hacer más figura de la que le corresponde. (1791 a 1869. aum. de ESCUDERO que se dice por desprecio...) [inc.: Aut // joc. y vulg.: Aut // desp.: 1791]

especular2. 4. fig. Efectuar operaciones comerciales o financieras, con la esperanza de obtener beneficios basados en las variaciones de los precios o de los cambios. Ú. frecuentemente con sentido peyorativo. [inc. y desp.: 1992]

esquirol. 2. despect. Obrero que trabaja cuando hay huelga o que se presta a realizar el trabajo abandonado por un huelguista. [inc. y desp. 1914]

estudiantón. despect. Estudiante aplicado, pero de escasas luces. (1803 a 1852. Se dice de los estudiantes estrafalarios y groseros.) (1791. aum. que por desprecio se dice...) [inc.: Aut // desp.: 1791, 1884 a 1992]

estudiantuelo, la. d. despect. de estudiante. [inc. y desp.: 1884]

-ete, ta. suf. de adjetivos y sustantivos, con valor diminutivo o despectivo, a veces no muy explícito: regordETE, calvETE, vejETE, historiETA, CasETA, palacETE. Muchas palabras han perdido esos valores: PeSETA, $j u-$ gUETE". [...] [inc. y desp.: 1992] fácil. 5. desus. Aplícase al que con ligereza se deja llevar del parecer de otro. Usáb. en sentido peyorativo. (1791 a 1832. por lo común se toma en mala parte...) (1780. regularmente se toma en mala parte...) [inc. y desp.: Aut]

farsa. 4. despect. Obra dramática desarreglada, chabacana y grotesca. [inc. y desp.: 1884]

fautor, ra. El que favorece y ayuda a otro. Hoy se usa más generalmente en sentido peyorativo. (1984. En mala parte.) (Aut. a 1783. Tómase tanto en buena como en mala parte.) [inc.: Aut a 1783, 1803 a 1992 // desp.: Aut. a 1783, 1869 a 1992]

feúco, ca. despect. fam. feúcho. [inc.: 1869 // fam. y desp.: 1936]

feúcho, cha. despect. fam., a veces afectuoso, con que se encarece y moteja la fealdad de una persona o cosa. [inc.: 1869 // fam.: 1869 a 1992 // desp.: 1936]

filosofastro. despect. Falso filósofo, que no tiene la calidad necesaria para ser considerado como tal. [inc.: 1832 // desp.: 1884]

finústico, ca. fam. despect. finolis. (1984. Fino. Dícese especialmente de la persona que exagera su cortesía en el trato social.) [inc., fam. y desp.: 1936]

flacucho, cha. despect. fam. Algo flaco. Ú. con frecuencia en sentido afectuoso. [inc.: 1852 // fam.: 1984 a 1992 // desp.: 1884 a 1956, 1984 a 1992]

floripondio. 2. fig. despect. Flor grande que suele figurar en adornos de mal gusto. [inc.: 1791 // desp.: 1936]

foliculario. despect. Folletista, periodista. [inc. y desp.: 1899]

fondón2, na. fam. y despect. Dícese de quien ha perdido la gallardía y agilidad por haber engordado. [inc., fam. y desp.: 1947]

fraguar. 2. fig. Idear, discurrir y trazar la disposición de alguna cosa. Se usa generalmente en sentido peyorativo. [inc.: Aut // desp.: 1884]

frailuco. despect. Fraile despreciable y de poco respeto. [inc.: 1791 // fam.: $1791 / /$ desp.: 1884]

frailuno, na. fam. despect. Propio de fraile. [inc., fam. y desp.: 1852] 
franchute, ta. despect. francés. [inc. y desp.: 1925]

fregona. Criada que sirve en la cocina y friega. Ú. en sentido despectivo. [inc.: Aut // desp.: 1925]

fritanga. Fritada, especialmente la abundante en grasa. A veces se usa en sentido despectivo. [inc. y desp.: 1925]

furcia. despect. prostituta, ramera. (1970. Mujer despreciable.) [inc.: 1970 // desp.: 1984] gabacho, cha. 4. fam. despect. francés. [inc.: 1803 // fam. y bax.: 1803 // fam.: 1817 a 1992 // desp.: 1925]

gabacho, cha. 5. fam. despect. Lenguaje español plagado de galicismos. [inc.: 1884 // desp.: 1992]

gato1. II cuatro gatos. expr. despect. para indicar poca gente y sin importancia. [inc. y desp.: 1925]

gentecilla. 2. despect. Gente ruin y despreciable. [inc.: Aut // desp.: 1884]

gentualla. despect. La gente más despreciable de la plebe. [inc.: Aut // desp.: 1884]

gentuza. despect. gentualla. [inc.: $1843 / /$ fam.: 1843 // desp.: 1884]

gimotear. despect. Gemir con insistencia y con poca fuerza, por causa leve. (1984. intr. fam. o despect. de gemir, dicho del gemir ridículamente, sin bastante causa.) [inc.: 1817 // fam.: 1817 a 1984 // desp.: 1925] godo, da. 4. despect. Argent., Col., Chile y Urug. Nombre con que se designaba a los españoles durante la guerra de la Independencia. [inc. y desp.: 1936]

gramática. II gramática parda. fam. Habilidad para conducirse en la vida y para salir a salvo o con ventaja de situaciones comprometidas. Suele tener sentido peyorativo. (1984. Suele tomarse en mala parte.) [inc.: Aut // fam.: 1803 a 1992 // desp.: 1984] gramatiquear. fam. despect. Tratar de materias gramaticales. [inc., fam. y desp.: 1925] gramatiquería. fam. despect. Cosa que pertenece a la gramática. [inc.: 1803 // fam.: 1803 a 1992 // desp.: 1925]

grandulón, na. fam. Argent. grandullón, especialmente el que se comporta como un niño. Ú. m. c. despect. [inc. y desp.: 1992] gringaje. desus. Argent. y Urug. Conjunto o grupo de gringos. Ú. m. con sent. despect. [inc. y desp.: 1984]

guindilla. 3. despect. y fam. Individuo del cuerpo de guardia municipal. [inc. y fam.: 1914] guindilla. 4. despect. y fam. agente de policía. [inc. y fam.: 1914]

halacuerda. despect. Mar. Marinero que solo entiende de aparejos y labores mecánicas. (1947. Halacabuyas.) [inc.: Aut // desp.: 1956]

hambre. II ser un muerto de hambre. despect. Carecer de lo necesario, a pesar de lo que se aparenta. [inc. y desp.: 1992]

hatajo. 2. despect. Grupo de personas o cosas. Un HATAJO de pillos; un HATAJO de disparates. (1884 a 1947. fam. fig. Conjunto, copia.) [inc.: 1780 // fam.: 1884 a 1984 // desp.: 1992]

hembraje. 2. rur. despect. Argent. y Urug. Conjunto o grupo de mujeres. [inc. y desp.: 1984]

hermanuco. despect. donado, el que pertenece a una orden religiosa en calidad de sirviente pero sin profesar. (1869. Nombre que se da por desprecio...) [inc. y desp.: 1817]

herrerón. aum. despect. de herrero. Herrero que no sabe bien su oficio. [inc.: $1803 / /$ desp.: 1884]

hierbajo. despect. de hierba. [inc. y desp.: 1914]

hijuco, ca. d. despect. de hijo, ja. [inc. y desp.: 1936]

homúnculo. d. despect. p.us. de hombre. [inc. y desp.: 1936]

hornaza. aum. despect. de horno. [inc. y desp.: 1936]

humoracho. despect. de humor. [inc. y fam.: 1925]

-ica. suf. de adjetivos, con valor iterativo y despectivo: acusica, IloncA, quejica. [inc. y desp.: 1992]

-ija. suf. de sustantivos femeninos, con frecuencia diminutivos, a veces despectivos: baratuJ, lagartıs. [inc. y desp.: 1992]

-ijo. suf. de sustantivos masculinos, que suele tener valor despectivo: amassıo, escondnנo, revoltuso. [inc. y desp.: 1992] 
-jjón, na. suf. de sustantivos y adjetivos, con matiz aumentativo: torajón, o bien despectivo: metıJón, sernJón. [inc. y desp.: 1992] individuo, dua. 7. f. despect. Mujer despreciable. [inc. y desp.: 1970]

ingeniosidad. 2. fig. Expresión o idea artificiosa y sutil. Ú. por lo general despectivamente. [inc. y desp.: 1925]

joto. coloq. despect. Méj. Marica, invertido.

[inc. y desp.: 1992]

jovenzuelo, la. despect. d. de joven. [inc.: 1925 // desp.: 1992]

latín. 2. Voz o frase latina empleada en escri-

to o discurso español. Suele tomarse en sentido peyorativo. (1984. en mala parte) (1852. Palabra o cláusula latina que...) [inc.: Aut // desp.: 1884]

latinajo. fam. despect. Latín malo y macarrónico. [inc.: Aut // vulg. y joc.: Aut a $1791 / /$ fam.: 1803 a 1992 // desp.: 1884]

latinajo. 2. fam. despect. Voz o frase latina usada en castellano. [inc., fam. y desp.: 1884]

levitín. d. fam. despect. de levita2. [inc., fam. y desp.: 1970]

liberalesco, ca. despect. de liberal, en política. [inc. y desp.: 1936]

libraco. despect. Libro despreciable. [inc.: 1843 // desp.: 1884]

libracho. despect. libraco. (1984. Libro despreciable.) [inc.: 1869 // desp.: 1884]

librejo. 2. despect. libraco. [inc.: $1803 / /$ desp.: 1884]

Iloradera. despect. Acción de llorar mucho por motivo liviano. [inc. y desp.: 1884]

lobo. II lobos de una camada. expr. fig. y fam.. Personas que por tener unos mismos intereses 0 inclinaciones no se hacen daño unas a otras. Ú. por lo común, en sentido peyorativo. [inc. y desp.: 1884]

Iugarejo. d. despect. de lugar. [inc.: 1803 // desp.: 1992]

machote2. despect. Especie de mazo. (1780 a 1791. Usase en la frase CASTRAR a MACHOTE...) [inc.: Aut a 1791, 1884 a $1992 / /$ desp.: 1884]

malejo, ja. d. despect. de malo. [inc.: 1884 // desp.: 1992] manga. 17. despect. Argent. Grupo de personas. Una MANGA de atorrantes. [inc. y desp.: 1992]

manga. II estar de manga. p.us. fig. y fam. Estar convenidas dos o más personas para un mismo fin. Tómase, por lo regular, en sentido peyorativo. [inc. y desp.: 1884]

manjorrada. desus. despect. Gran cantidad de manjares ordinarios. [inc.: 1803 // desp.: 1884]

maqueto, ta. despect. En el País Vasco, inmigrante de otra región española. [inc. y desp.: 1992]

maracucho, cha. despect. y fam. Venez. maracaibero. [inc.: 1956 // fam. y desp.: 1970] marmota. 4. fig. fam. y despect. criada, mujer dedicada al servicio doméstico. [inc., fam. y desp.: 1984]

marquesote. aum. despect. de marqués. (1803 a 1852. suele decirse por desprecio o burla.) [inc. y desp.: 1803]

marrano1. fig. Aplicábase como despectivo al converso que judaizaba ocultamente. (1936. Aplicábase como despectivo a los judíos.) [inc. y desp.: 1936]

marras. II lo de marras. loc. fam. con que se designa despectiva o humorísticamente algo consabido por el hablante y el oyente, ahorrando la necesidad de mencionarlo explícitamente. [inc., fam. y desp.: 1984]

matojo. despect. de mata1, planta de tallo bajo, ramificado y leñoso. [inc. y desp.: 1899] mayorazguete, ta. d. despect. de mayorazgo. (1869. fam. En tono de desprecio...) [inc. y desp.: 1852]

medianejo, ja. fam. despect. de mediano. Menos que mediano. [inc.: 1869 // desp.: 1992]

melifluamente. fig. Dulcemente, con grandísima suavidad y delicadeza. Ú. m. en sent. peyorativo. [inc.: Aut // desp.: 1992]

melifluo, flua. 2. fig. Dulce, suave, delicado y tierno en el trato o en la manera de hablar. Ú. m. en sent. peyorativo. [inc.: Aut // desp.: 1992]

mercachifle. 2. despect. Mercader de poca importancia. (1822 a 1843. Buhonero.) (Aut. a 1817. El que vende, llevando consigo to- 
dos sus géneros.) [inc.: Aut a 1817, 1852 a 1992 // fam.: 1852 a 1869 // desp.: 1884]

miedica. despect. fam. Miedoso. [inc. y desp.: 1992]

milico. despect. Argent., Bol., Chile, Ecuad.,

Perú y Urug. Militar, soldado. [inc. y desp.: 1970]

miseriuca. d. despect. de miseria. [inc. y desp.: 1936]

mondonga. despect. p.us. Criada zafia.

(1843. fam. Nombre que se da por desprecio a las criadas, como fregatriz.) (1780 a 1791. Nombre que daban en palacio a las criadas de las damas de la Reina.) [inc.: Aut // fam.: 1822 a 1869 // desp.: 1803]

monicaco. despect. Hombre de mala traza.

[inc. y desp.: 1899]

monteruca. despect. de montera1 de la cabe-

za. [inc. y desp.: 1869]

moñajo. despect. de moño. [inc. y desp.: 1925]

morondanga. II de morondanga. loc. despect.

Despreciable, de poco valor. [inc. y desp.: 1970]

muerto. II ser un muerto de hambre. fr. fig. y despect. Ser un miserable, un mezquino. [inc. y desp.: 1992]

mujeruca. despect. de mujer. [inc. y desp.: 1936]

musicastro. despect. de músico, persona que profesa la música. [inc. y desp.: 1936]

navajo. despect. de nava. [inc. y desp.: 1925] niñato2. Dícese del jovenzuelo petulante y presentuoso. Suele emplearse con valor despectivo. [inc. y desp.: 1984]

niño, ña. 5. fig. En sent. despect., que obra con poca reflexión y advertencia. (1899 a Aut. y se suele usar para desprecio.) [inc. y desp.: Aut]

ojo. II ojo de breque. fig. y fam. El pintarroso y remellado. Ú. t. en sent. despect. [inc.: Aut // fam. y desp.: 1803]

-ón1, na. suf. de sustantivos y adjetivos, derivados de sustantivos, adjetivos y verbos, de valor aumentativo, intensivo o expresivo: barracón, inocentón; despectivo: llorón, mirón. [...]. [inc. y desp.: 1992] oportunismo. Actitud o conducta sociopolítica, económica, etc., que prescinde en cierta medida de los principios fundamentales, tomando en cuenta las circunstancias de tiempo y lugar. Úsase a veces con valor peyorativo. [inc.: 1914 // desp.: 1984]

otro, tra. II otra, u otro, que tal. expr. fam. con que se da a entender la semejanza de cualidades de algunas personas o cosas. Se usa generalmente en sentido peyorativo. (1984. Tómase, [...], en mala parte.) (1869. Hoy solo [...] en el estilo familiar). [inc. y fam.: 1817 // desp.: 1884]

paja. II no haberle echado uno a otro paja ni cebada. fr. fig. y despect. No conocer o no haber tratado al sujeto de quien se habla o se pide informe. [inc.: 1803 // fam.: 1803 a 1869 // desp.: 1852]

pajarraco. despect. Pájaro grande desconocido, o cuyo nombre no se sabe. [inc.: Aut // desp.: 1884]

pajuncio. despect. paje. [inc. y desp.: 1832]

palabreja. d. despect. Palabra de escasa importancia o interés en el discurso. [inc. y desp.: 1936]

palabrota. despect. Dicho ofensivo, indecente o grosero. (1869. Palabrada.) [inc.: $1843 / /$ desp.: 1884]

papelorio. despect. Fárrago de papel o de papeles. [inc. y desp.: 1925]

papelote1. despect. Papel o escrito despreciable. [inc.: 1843 // desp.: 1884]

papelucho. despect. Papel o escrito despreciable. [inc.: 1843 // desp.: 1884]

papelujo. despect. papelucho. [inc. y desp.: 1970]

paporreta. despect. Perú. Repetición mecánica de lo que se ha aprendido de memoria sin entenderlo $\mathrm{o}$ entendiéndolo a medias. [inc. $\mathrm{y}$ desp.: 1984]

paporretear. despect. Perú. Aprender de memoria sin entender lo que se aprende o entendiéndolo a medias. [inc. y desp.: 1984]

pasioncilla. 2. despect. Movimiento ruin del ánimo en contra de alguna persona. [inc. y desp.: 1925]

paternalismo. Tendencia a aplicar las formas de autoridad y protección propias del padre 
en la familia tradicional a relaciones sociales de otro tipo; políticas, laborales, etc. Ú. frecuentemente con carácter peyorativo. [inc. y desp.: 1984]

peine. 8. fam. fig. púa, persona astuta. Tómase ordinariamente en sentido peyorativo. Mariano es un buen PEINE. (1984. en mala parte). [inc., fam. y desp.: 1884]

pelo. II de medio pelo. loc. fig. y fam. despect.

Dícese de las personas que quieren aparentar más de lo que son, o de las cosas de poco mérito o importancia. [inc.: 1884 // desp.: 1992]

periodicucho. despect. de periódico. Periódico despreciable. [inc. y desp.: 1936]

perote. despect. And. Natural o vecino de Álora, en la provincia de Málaga. [inc. y desp.: 1936]

personilla. despect. Persona muy pequeña de cuerpo o de mala traza, o condición. (Aut. a 1832. Se usa / úsase regularmente por desprecio...) [inc. y desp.: Aut]

pesetero, ra. 2. Se decía de lo que costaba o valía una peseta. A veces con uso despectivo. Coche PESETERO. [inc. y desp.: 1936] pigmeo, a. fig. Muy pequeño. Apl. a pers., ú. t. c. s., y a veces a animales. Gallina PIGMEA. En ocasiones, ú. con valor despect. (1899. Aplícase a las personas o cosas muy pequeñas.) [inc.: Aut // desp.: 1984]

pijotero, ra. Se dice despectivamente de lo que produce hastío, cansancio u otras cosas, según el sustantivo a que se aplica. [inc. y desp.: 1936]

pinche. despect. Méj. Despreciable, mezquino, poca cosa. Es voz malsonante. [inc., desp.: 1992]

pisco2. 2. despect. Col. Individuo de poca o ninguna importancia. [inc. y desp.: 1984]

pispajo. 3. En sent. despect., se aplica a personas desmedradas o pequeñas, especialmente niños. [inc. y desp.: 1970]

pitoche. despect. de pito1. [inc. y desp.: 1925]

plumífero, ra. 2. despect. El que tiene por oficio escribir. [inc. y desp.: 1970]

poblacho. despect. Pueblo ruin, y destartalado. [inc.: 1852 // desp.: 1884] policíaco, ca o policiaco, ca. Relativo o perteneciente a la policía. Ú. a veces en sent. despect. [inc. y desp.: 1914]

politicastro. despect. Político inhábil, rastrero, mal intencionado, que actúa con fines y medios turbios. [inc. y desp.: 1899]

polizonte. despect. Agente de policía. [inc. y desp.: 1884]

ponchazo. Il a los ponchazos. loc. Argent. De la mejor manera posible y con esfuerzo, dentro de la falta de medios o recursos. Ú. t. en sent. despect. [inc. y desp.: 1992]

preceptoril. despect. Propio de un preceptor o relativo a él. [inc. y desp.: 1925]

púa. 9. fig. y fam. Persona sutil y astuta. Se usa generalmente en sentido peyorativo (1984. en mala parte). Joaquín es buena PÚA. (1780 a 1803. Sutileza, o agudeza cautelosa ...: fulano es buena PúA. [inc.: Aut // fam.: 1884 a 1992 // desp.: 1817]

querindango, ga. despect. querido. [inc.: 1970 // desp.: 1992]

ralea. 2. despect. Aplicado a personas, raza, casta o linaje. [inc.: 1837 // desp.: 1925]

rapavelas. despect. Sacristán, monaguillo u otro dependiente de una iglesia. (1984. Vulgarismo por sacristán...) [inc.: 1936 // vulg.: 1936 a 1984 // desp.: 1992]

ratón. II ratón de biblioteca. fig. Erudito que con asiduidad escudriña muchos libros. Tómase por lo común en sentido peyorativo. [inc. y desp.: 1970]

recalvastro, tra. despect. Calvo desde la frente hasta la coronilla. [inc. y desp.: 1884] repartija. fam. Argent. y Chile. Reparto desordenado, a la rebatiña. Ú. m. con sentido peyorativo. [inc. y desp.: 1992]

retórica. 2. despect. Uso impropio o intempestivo de este arte. [inc. y desp.: 1956] retrógrado. 2. fig. despect. Partidario de instituciones políticas o sociales propias de tiempos pasados. [inc.: 1884 // desp.: 1956]

ricachón, na. despect. de rico, o ricacho. [inc. y desp.: 1936]

roto, ta. O. y N. Argent. y Perú. fam. despect. chileno. [inc., fam. y desp.: 1925] 
-rro. suf. que suele tener valor diminutivo y despectivo. Toma las formas -arro, -orro y -orrio: guijaRRO, ventORRO, villoRRIO. [inc. y desp.: 1992]

runa2. Hombre indio. Ú. a veces con valor despect. [inc. y desp.: 1984]

sabidillo, Ila. despect. Que presume de entendido y docto sin serlo o sin venir a cuento. [inc. y desp.: 1852]

sacristanesco, ca. despect. Perteneciente o relativo al sacristán. [inc. y desp.: 1956]

saltatumbas. fig. y despect. fam. Clérigo que se mantiene principalmente de lo que gana asistiendo a los entierros. [inc.: $1884 / /$ fam.: 1884 a 1992 // desp.: 1925]

sargentona. fam. despect. Mujer corpulenta, hombruna y de dura condición. (Aut. a 1803. sargentón: Se apropia regularmente a alguna mujer por [...] ser fuerte, robusta $\mathrm{y}$ varonil en sus palabras o acciones.) [inc.: Aut a 1803, 1925 a 1992 // fam. y desp.: 1925]

$-s c o, c a$. suf. de adjetivos y sustantivos. En los adjetivos suele denotar relación o pertenencia, y a veces tiene matiz despectivo. Aparece en las formas -asco, -esco, -isco, izco, -usco, -uzco: bergamasco, burlesco, morisco, blanquizco, pardusco, negruzco. [...] [inc. y desp.: 1992]

semiculto, ta. 2. Dícese de la persona que solo tiene una mediana cultura general. Ú. $\mathrm{m}$. c. s. y frecuentemente con valor peyorativo. [inc. y desp.: 1984]

señoritingo, ga. despect. de señorito. [inc. y desp.: 1925]

ser2. II ser de lo que no hay. fr. fam. Dicho de una persona o cosa, no tener igual en su clase. Se usa por lo general con sentido peyorativo (1984. en mala parte). [inc., fam. y desp.: 1925]

sofista. 2. En la Grecia antigua, se llamaba así a todo el que se dedicaba a la filosofía. Desde los tiempos de Sócrates el vocablo tuvo significación despectiva. (1899. Filósofo o retórico de la antigüedad clásica.) [inc.: Aut // desp.: 1925]

soflama. 4. fig. despect. Discurso, alocución, perorata. (1899. Ficción de palabras con que uno intenta engañar ó chasquear.) [inc.: Aut // desp.: 1925]

soldadote. aum. despect. de soldado. Se usa principalmente hablando del militar de alta graduación que se distingue por la brusquedad de sus modales. [inc. y desp.: 1947] soniquete. despect. de son. [inc. y desp.: 1925]

sotreta. rur. despect. Argent., Bol. y Urug. Dícese de la persona o animal lleno de defectos. [inc.: 1956 // desp.: 1992]

suche. 4. despect. Chile y Nicar. Empleado de última categoría, subalterno. [inc. y desp.: 1925]

suficiencia. 3. fig. despect. Presunción, engreimiento, pedantería. [inc. y desp.: 1956] sugestión. 2. Idea o imagen sugerida. Se usa generalmente en sentido peyorativo (1984. en mala parte). Las SUGESTIONES del demonio. [inc.: Aut // desp.: 1884]

suripanta. 2. despect. Mujer ruin, moralmente despreciable. [inc. y desp.: 1925]

suyo, ya. II hacer uno de las suyas. fr. fam. Obrar, proceder según su genio y constumbre. Se usa generalmente en sentido peyorativo. [inc. y desp.: 1936]

tablajero. Ar. despect. Practicante del hospital. [inc.: 1803 // desp.: 1925]

tal. II tal para cual. expr. fam. con que se denota igualdad o semejanza moral entre dos personas. Se usa generalmente en sentido peyorativo (1984. en mala parte). [inc.: Aut // fam. y desp.: 1884]

tal. II tal por cual. loc. despect. De poco más o menos. [inc. y desp.: Aut]

tal. II una tal. loc. despect. Una ramera. [inc.: 1869 // fam.: 1869 a 1914 // desp.: 1884] tatarrete. despect. de tarro, vasija. [inc. y desp.: 1925]

tela. II tela de cebolla. 2. fig. despect. tela de poca consistencia. [inc. y desp.: 1925]

tinterillo. fig. y fam. despect. Oficinista, cagatintas. [inc., fam. y desp.: 1936]

tipejo. despect. tipo, persona ridícula y despreciable. [inc.: 1925 // desp.: 1992]

tipo. 9. Individuo, hombre, frecuentemente con matiz despectivo. [inc. y desp.: 1970] 
tiracuero. despect. Zapatero de oficio. [inc. y desp.: 1925]

tirajo. despect. de tira de papel, tela, etcétera. [inc. y desp.: 1899]

tontucio, cia. despect. de tonto; medio tonto. [inc. y desp.: 1925]

tragasantos. fam. despect. Persona beata que tiene gran devoción a las imágenes de los santos. [inc., fam. y desp.: 1925]

trapajo. despect. de trapo. (1869. Pedazo de paño o lienzo roto y viejo.) [inc.: Aut // desp.: 1884]

tropa. despect. gentecilla. [inc. y desp.: 1925] tutumpote. Sto. Dom. mandamás, el que todo lo puede, dicho con sent. irónico y despectivo. [inc. y desp.: 1984]

-uelo, la. [...] Algunas de las palabras formadas con estos sufijos tienen valor despectivo: mujerzuela, escritorzuelo; [...]. [inc. y desp.: 1992]

uña. II no tener uñas para guitarrero. fr. fig. y fam. Argent., Par. y Urug. Carecer una persona de las cualidades necesarias para llevar a cabo una tarea. Ú. m. c. despect. [inc.: 1970 // fam. y desp.: 1992] vejestorio. despect. Persona muy vieja. (1869. Vejete.) [inc.: 1832 // desp.: $1884]$

ventajear. 2. En sent. peyorativo, sacar ventaja mediante procedimientos reprobables 0 abusivos. [inc. y desp.: 1984]

ventorro. despect. Venta de hospedaje pequeña o mala. [inc.: Aut // desp.: 1899]

viaje1. II juen viaje! 2 . expr. despect. con que se denota lo poco que importa que una cosa se pierda o uno se vaya. (Aut. a 1832. Se usa (también) como expresión de desprecio...) [inc. y desp.: Aut]

vidorria. 2. fam. despect. Col., P. Rico y Venez. Vida arrastrada y triste. [inc., fam. y desp.: 1925]

villorrio. despect. Población pequeña y poco urbanizada. (1780 a 1869. Población muy corta. Se usa por desprecio.) (Aut. Es de estilo familiar, y se usa por desprecio.) [inc. y desp.: Aut]

vulgacho. despect. Ínfimo pueblo o vulgo. [inc.: Aut // desp.: 1884] 